\title{
Induction of Pseudomonas syringae pv. tomato DC3000 MexAB-OprM Multidrug Efflux Pump by Flavonoids Is Mediated by the Repressor PmeR
}

\author{
Paola Vargas, ${ }^{1}$ Antonia Felipe, ${ }^{1}$ Carmen Michán, ${ }^{2}$ and María-Trinidad Gallegos ${ }^{1}$ \\ ${ }^{1}$ Department of Soil Microbiology and Symbiotic Systems, Estación Experimental del Zaidín (EEZ-CSIC), Granada, Spain; \\ ${ }^{2}$ Department of Biochemistry and Molecular Biology, University of Cordoba, Spain
}

Submitted 29 March 2011. Accepted 27 May 2011.

\begin{abstract}
In this study, we have analyzed the expression of the Pseudomonas syringae pv. tomato DC3000 mexAB-oprM efflux pump operon and of the regulatory gene $p m e R$, and we have investigated the role of the PmeR protein on transcription from both promoters. We demonstrate that mexAB-oprM and pmeR are expressed in vivo at a relatively high and moderate basal level, respectively, which, in both cases, increases in the presence of different flavonoids and other compounds, such as butyl and methylparaben. We show that PmeR is the local repressor of the mexABoprM promoter and is able to regulate its own expression. The mechanism for this regulation includes binding to a pseudopalindromic operator site which overlaps both mexAB-oprM and pmeR promoters. We have also proven that flavonoids are able to interact with PmeR and induce a conformational change that interferes with the DNA binding ability of PmeR, thereby modulating mexAB-oprM and pmeR expression. Finally, we demonstrate by in vivo experiments that the PmeR/MexAB-OprM system contributes to the colonization of tomato plants. These results provide new insight into a transcriptional regulator and a transport system that play essential roles in the ability of $P$. syringae pv. tomato DC3000 to resist the action of flavonoids produced by the host.
\end{abstract}

Microorganisms are continuously exposed to naturally occurring deleterious chemicals, such as natural antibiotics produced by members of microbial communities, fungi, and plants or detergents such as bile salts present in the intestinal tract of higher animals. Apart from these toxins, human activity also has led to the production of a great diversity of noxious organic and inorganic chemicals (xenobiotics) and, furthermore, semisynthetic antibiotics or biocides have been specifically developed to act as antimicrobial agents. These toxic compounds usually affect the structure of biological membranes or impair biosynthetic pathways essential for microbial growth. Nevertheless, bacteria display resistance to their action due to intrinsic long-standing mechanisms that protect the cells. Among the mechanisms underlying the resistance to toxic chemicals, active exclusion catalyzed by efflux pumps is widespread. Efflux pumps either can be specific for one substrate or can

Corresponding author: M.-T. Gallegos; Telephone: +34 958181600 ext. 133; Fax: +34 958 129600; E-mail: maritrini.gallegos@eez.csic.es

* The $\boldsymbol{e}$-Xtra logo stands for "electronic extra" and indicates that Figure 8 appears in color online. transport a range of structurally dissimilar compounds, including antibiotics of different chemical classes, biocides, dyes, detergents, metabolic inhibitors, and organic solvents ( $\mathrm{Li}$ and Nikaido 2009). The pumps that transport several compounds are associated with multidrug resistance (MDR) and have clinical relevance because they can render bacterial infections untreatable by the agents of choice.

Plants produce a vast array of natural products, many of which have evolved to confer selective advantage against microbial attack. Flavonoids, isoprenoids, and alkaloids compose three major classes of secondary metabolites synthesized by higher plants that have been considered important for protection against pathogens. They may be preformed compounds present in healthy plant tissue or may be synthesized de novo in response to pathogen attack (Dixon 2001; Osbourn 1996). Therefore, successful pathogens must be able to circumvent the toxic effects of these plant antimicrobials (Van Etten et al. 2001) and, for that, they have MDR efflux pumps belonging to the same families as those present in bacteria that infect humans and animals.

Five families of bacterial efflux pump associated with MDR have been reported: the ATP-binding cassette (ABC) superfamily, the major facilitator superfamily (MFS), the multidrug and toxic-compound extrusion (MATE) family, the small multidrug resistance (SMR) family, and the resistance-nodulationcell division (RND) family (Saier and Paulsen 2001). Efflux pumps of the RND family expressed by gram-negative bacteria are organized as tripartite systems: a transporter protein located in the cytoplasmic membrane (acting as an energy-dependent extrusion pump) is attached through a membrane fusion protein to an outer membrane protein. The latter is a channel which circumvents the outer membrane, allowing the discharge of the toxic compound into the external medium (Eswaran et al. 2004; Murakami et al. 2006; Poole 2003). Thus, efflux through RND pumps is driven by the proton motive force and allows the removal of toxic compounds across the inner and outer membranes of the cell envelope bypassing the periplasm.

Most RND efflux pumps are under transcriptional or translational control to maintain low levels of expression, because overexpression of integral membrane proteins coupled to the proton-motive force has deleterious effects (Hillen and Berens 1994; Johanesen et al. 2001, Ma et al. 1996). Thus, the expression of most genes encoding efflux pumps is controlled by transcriptional regulators (sometimes activators but predominantly repressors), whose genes are often located adjacent to them. Nevertheless, in addition to this specific or local regulation, the expression of some pumps is under an additional level of control by various global regulators (Li and Nikaido 2009). 
The broad substrate specificity exhibited by the transporter contrasts with the limited chemical specificity shown by the vast majority of ligand binding proteins. However, the phenomenon of multidrug recognition is not exclusively confined to multidrug transporters, because several transcriptional regulators promote transporter expression in response to structurally dissimilar toxic compounds. The peculiarity of these systems is that the regulators controlling the expression of the transporters respond to the same range of compounds that the transporter extrudes (Grkovic et al. 1998; Lomovskaya et al. 1995; Ma et al. 1996; Terán et al. 2003, 2006).

Several RND transporters have been characterized in phytopathogenic bacteria and their physiological function or role in virulence determined. Agrobacterium tumefaciens IfeAB is involved in the competitive colonization of alfalfa roots by reducing cellular accumulation of isoflavonoids (Palumbo et al. 1998). Erwinia chrysanthemi possesses two AcrAB systems, which are involved in the resistance to the plant antimicrobial peptide thionin and play an essential role in colonization of chicory leaves (Maggiorani-Valecillos et al. 2006). Also in E. chrysanthemi, it has been shown that the inactivation of TolC has a dramatic effect on pathogenesis (Barabote et al. 2003). TolC is the outer membrane component of several MDR efflux pumps in the RND family; thus, this mutation probably affects the function of a large number of transporters at the same time. It was demonstrated that the RND-type AcrAB efflux system plays an important role in virulence of $E$. amylovora, the causal agent of fire blight in various members of the family Rosaceae, because it is required for resistance to antimicrobial plant metabolites and for successful colonization of the host plant (Burse et al. 2004). Moreover, two transporters belonging to the RND family have been involved in secretion of phytotoxins: Burkholderia glumae BGR1 produces a broad-hostrange phytotoxin, called toxoflavin, which is transported by ToxGHI (Kim et al. 2004); and the PseABC system was identified in the syr-syp genomic island of Pseudomonas syringae pv. syringae required for biosynthesis of syringomycin and syringopeptin. Disruption of the $p s e C$ gene resulted in substan- tial reduction of phytotoxin secretion and virulence (Kang and Gross 2005).

On the other hand, the importance of plant signals for the regulation of different virulence factors has been well established (Cornelis and van Gijsegem 2000). However, the regulatory circuits acting on the expression of RND transporters in response to plant-produced compounds constitute an unexplored field. In $P$. syringae pv. phaseolicola 1448A, $P$. syringae pv. syringae $\mathrm{B} 728 \mathrm{a}$, and $P$. syringae pv. tomato DC3000, whose host ranges are different (1448A and B728a cause disease in bean, and DC3000 is pathogenic for tomato and Arabidopsis), the RND transporter MexAB-OprM (PSPTO_4303-4304-4305) was shown to be involved in tolerance to a broad range of compounds (antibiotics, plant-derived antimicrobials, detergents, and dyes) and in the ability to multiply in planta (Stoitsova et al. 2008). A gene encoding a transcriptional regulator, pmeR (PSPTO_4302), was identified upstream of the mexAB-oprM structural genes (Stoitsova et al. 2008). Its deduced amino acid sequence exhibited a high degree of identity to members of the TetR family of transcriptional repressors, including proteins of different $P$. syringae pathovars (90 to $95 \%$ identity), regulators of $P$. fluorescens (68-74\% identity), such as EmhR (Hearn et al. 2003); P. putida (66 to $67 \%$ identity), such as TtgR (Terán et al. 2003); and Erwinia spp. (42 to 44\% identity), such as AcrR of E. amylovora (Burse et al. 2004), among others. However, no significant similarity was found to MexR, a member of the MarR family of bacterial transcriptional regulators, which negatively regulates the mexAB-oprM operon in $P$. aeruginosa (Poole et al. 1996). The homology of the pmeR gene product with previously described repressor proteins and its proximity to the efflux pump operon suggested that PmeR regulates mexAB-oprM expression and probably its own expression, as is the case for other regulators of the TetR family (Aramaki et al. 1995; Guilfoile and Hutchinson 1992; Hillen and Berens 1994; Terán et al. 2003).

The aim of this study was to analyze the role of the PmeR protein in the expression of the mexAB-oprM efflux pump operon and its own gene, pmeR. Also, we intended to deter-

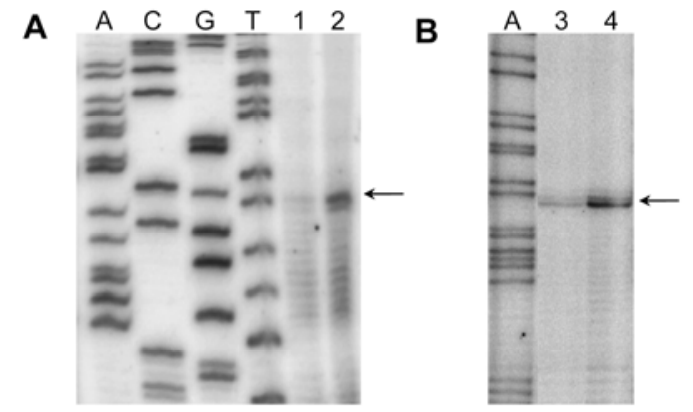

C

CagGGCAATAAGACCTCAAAAGATTCACCTCATGCGTGCATCTGGTGCATGCCTTGAGGTATGACCGGGCGCATTTGTCTCGCCTT G29:CCGTTATTCTGGAGTTTTCTAAGTGGAGTACGCACGTAGACCACGTACGGAACTCCATACTGGCCCGCCGTAAACAGAGCGGAA pmeR

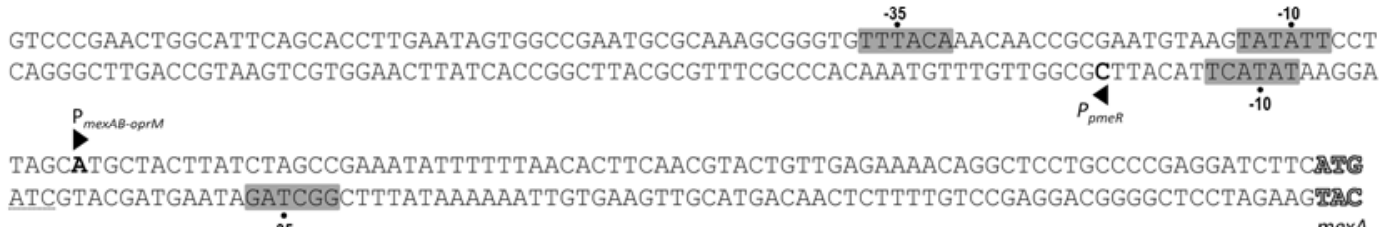
.$\dot{35}$

Fig. 1. Determination of the transcription start sites of $\mathbf{A}$, the mexAB-oprM operon and $\mathbf{B}$, the pmeR gene by primer extension analysis. Total RNAs of wild type (lanes 1 and 3) and DC3000R (lanes 2 and 4) cells grown in Luria-Bertani medium were prepared and used for the reverse transcription reactions to generate the runoff cDNAs. Lanes A, C, G, and T contain the products of the dideoxy sequencing reactions with the same primers as those used for the respective reverse transcriptions. Runoff cDNAs are indicated by arrows. $\mathbf{C}$, Nucleotide sequence of the pmeR-mexA intergenic region. The -10 and -35 positions of $\mathrm{P}_{p m e R}$ and $\mathrm{P}_{m e x A}$ are indicated by a dot, the +1 and the direction of transcription are marked with an arrowhead, and the initiation codons are also marked. 
mine the natural ligands of the regulatory protein PmeR and the regulatory network involved in the expression of the efflux pump, in order to elucidate the role of the PmeR/MexABOprM system in plant pathogenesis.

\section{RESULTS}

\section{Localization of the promoter elements and} transcription start points for mexAB-oprM and pmeR.

Previous inspection of the sequence upstream of mex $A B$ oprM had revealed a divergently transcribed open reading frame (ORF), pmeR, postulated to regulate mexAB-oprM transcription. To determine the role of PmeR as transcriptional regulator in $P$. syringae pv. tomato, we constructed a pmeRnull mutant by marker exchange mutagenesis using the suicide plasmid pPVG-R $\Omega K m$. Polymerase chain reaction (PCR) and Southern blot were used to confirm integration of the $\Omega \mathrm{Km}$ interposon in the genomic pmeR locus (not shown).

To localize the actual promoter or promoters used by mexAB-oprM and pmeR, the transcription start point for both operons was determined in the wild type and DC3000R (pmeR disruptant) using primer extension analysis. Regardless of the
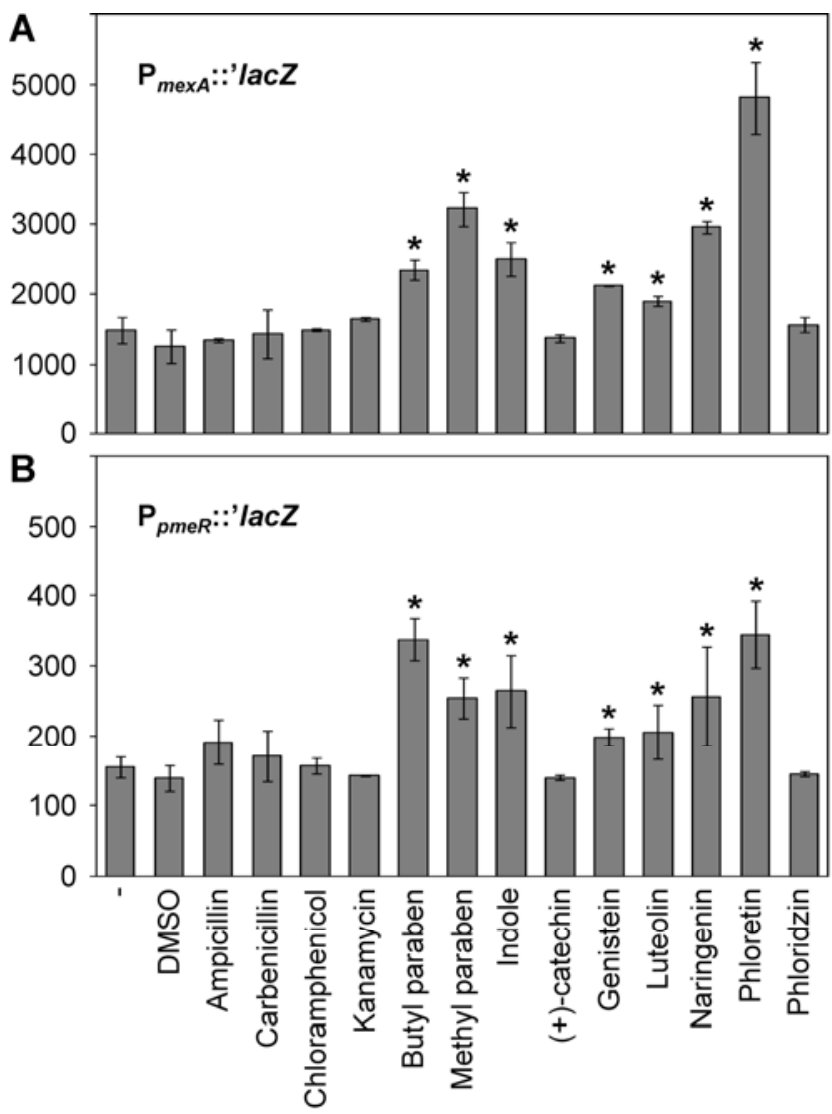

Fig. 2. Expression of mexAB-oprM and pmeR promoters in the presence of different antimicrobial compounds. The $\beta$-galactosidase activity from $\mathbf{A}$, the mexAB-oprM (pPV1A) and $\mathbf{B}$, pmeR (pPV2R) promoters was determined in DC3000 cultures grown to an optical density at $660 \mathrm{~nm}$ of 2 in the absence (-) or in the presence of different chemicals at subletha concentrations: ampicillin $(3 \mu \mathrm{g} / \mathrm{ml})$, butylparaben $(0.5 \mathrm{mM})$, carbenicillin $(40 \mu \mathrm{g} / \mathrm{ml}),(+)$-catechin $(1 \mathrm{mM})$, chloramphenicol $(2 \mu \mathrm{g} / \mathrm{ml})$, genistein $(0.5 \mathrm{mM})$, indole $(0.3 \mathrm{mM})$, kanamycin $(0.1 \mu \mathrm{g} / \mathrm{ml})$, luteolin $(0.5 \mathrm{mM})$, methylparaben $(0.4 \mathrm{mM})$, naringenin $(1 \mathrm{mM})$, phloretin $(0.4 \mathrm{mM})$, and phloridzin $(1 \mathrm{mM})$. Compounds were dissolved in dimethyl sulfoxide when needed. Results shown are the mean of three different experiments with their respective standard deviations; * indicates that increases of $\beta$ galactosidase activity are significant with respect to the noninduced condition as determined by one-way analysis of variance $(P<0.05)$. growth conditions (not shown), the mexAB-oprM operon was transcribed from a single promoter (Fig. 1A), because only a specific band containing runoff cDNA corresponding to mexABoprM was detected. We identified the transcription initiation site of mexA at the A located $79 \mathrm{bp}$ upstream of its first ATG. We predicted that the -10 and -35 sequences of the mex $A B$ oprM promoter are TATATT and TTTACA, respectively, with an 18-bp spacer (Fig. 1C), which are similar to promoter sequences recognized by the $\sigma^{70}$-RNA polymerase (Lisser and Margalit 1993). For pmeR, one specific band of runoff cDNA was detected on the RNA samples from the wild-type and DC3000R strains but the intensity of this band in the wild-type strain seemed to be substantially less than in the null mutant (Fig. 1B). This suggests that the pmeR gene is autorepressed, as is the case for other negative regulatory genes such as tet $R$ (Hillen and Berens 1994). Thus, we determined the transcription start site of pmeR at $\mathrm{G}-154$ with respect to its first ATG and predicted that the -35 and -10 sequences of the pmeR promoter are GGCTAG and TATACT with a 20-bp spacer (Fig. $1 C)$, which also correspond to a $\sigma^{70}$-RNA polymerase promoter. The location of the start sites indicates that the promoters of the divergently transcribed pmeR and mexA overlap and are both under the control of the same regulator, probably PmeR.

\section{Substrates of MexAB-OprM act as inducers of $\operatorname{mexAB-oprM}$ and pmeR expression.}

To study whether the compounds identified as substrates of the efflux pump (Stoitsova et al. 2008) also influenced in vivo gene expression of the mexAB-oprM efflux pump operon and the pmeR gene, we constructed two sets of plasmids (pPV1A and $\mathrm{pPV} 2 \mathrm{R}$ ) in which the same pmeR-mexA intergenic region fragment was cloned in both directions, producing fusions of the mexA and the pmeR promoters, respectively, to lacZ. These plasmids were introduced into the wild-type strain and $\beta$-galactosidase ( $\beta$-gal) activity was determined in the absence and in the presence of various MexAB-OprM substrates: butylparaben, (+)-catechin, genistein, indole, luteolin, methylparaben, naringenin, phloridzin, and phloretin (Fig. 2A and B). The $\beta$ gal activity of $\mathrm{P}_{\text {mexAB-oprM }}$ increased significantly in the presence of phloretin, methyl paraben, and naringenin, with phloretin being the most effective inducer. Addition of indole and butyl paraben resulted in moderate induction of the $\beta$-gal activity, whereas addition of genistein and luteolin induced $\beta$-gal activity only very slightly, and addition of other antibiotics (ampicillin, carbenicillin, chloramphenicol, or kanamycin) and flavonoids (phloridzin or $(+)$-catechin) did not induce $\beta$-gal activity at all (Fig. 2). $\mathrm{P}_{\text {pmeR }}$ exhibited lower overall levels of expression than those of $\mathrm{P}_{\text {mexAB-oprM }}$ but a similar pattern of expression and induction (Fig. 2). This suggests a common mechanism of regulation for both promoters, also consistent with the fact that both promoters fully overlap.

\section{The pmeR gene encodes a repressor of $\operatorname{mex} A B$-oprM and pmeR expression.}

The homology of the pmeR gene product with repressor proteins of the TetR family of transcriptional regulators, together with its proximity to the efflux pump operon as well as the results presented above, suggest that PmeR acts locally, repressing mexAB-oprM and probably its own expression, as is the case for other transcriptional regulators of the TetR family (Hernández et al. 2009; Hillen and Berens 1994; Hirooka et al. 2007). To confirm this hypothesis, strains DC3000 (wild type),

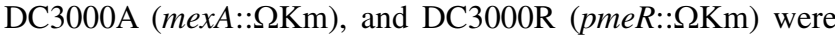
used to assess mexAB-oprM and pmeR expression by quantitative reverse-transcription polymerase chain reaction (RT-PCR) in the absence and in the presence of phloretin, the compound 
inducing the highest expression from both promoters (Fig. 2). We observed that, in the wild type, both operons were induced 3.6- and 2.5-fold, respectively, by phloretin but not in response to any of the antibiotics tested (i.e., carbenicillin, chloramphenicol, nalidixic acid, tetracycline, or gentamicin) (not shown). In the DC3000A mutant, the pmeR promoter behaved similarly to the wild type; however, in the DC3000R mutant, the levels of the mexA transcripts were 3.6-fold higher than in its parental strain, and a slight 1.3-fold increase in transcription was detected in the presence of phloretin (Fig. 3). This suggests that there may be an additional transcriptional regulator, probably an activator, which induces expression of mexA in the presence of phloretin. Given the nature of the mutation (the insertion of an interposon with transcriptional and translational terminators), the analysis of mexA and pmeR RNAs in DC3000A and DC3000R, respectively, was not possible.

To further confirm the effect of PmeR over both promoters, $\beta$-gal assays were carried out in the wild-type and mutant strains throughout the growth curve in the absence and in the presence of phloretin (Fig. 4). In the wild-type strain, the basal activity of both promoters (in the absence of phloretin) remained substantially constant throughout the growth curve (Fig. 4A). In the presence of phloretin, expression from both promoters increased with respect to the basal level, up to 2.5fold in the case of $\mathrm{P}_{\text {mexAB-opr }}$ and 1.7-fold in the case of $\mathrm{P}_{\text {pmeR }}$. However, expression from $\mathrm{P}_{\text {mexAB-oprM }}$ was significantly higher than that of $\mathrm{P}_{\text {pmeR }}$ in both the absence and presence of phloretin (Fig. 4A).

It was observed that inactivation of PmeR in DC3000R caused an increase of approximately threefold on the basal expression of $\mathrm{P}_{\text {mexAB-oprM }}$ compared with the activity in the wildtype strain (Fig. 4B), indicating that PmeR acts as a repressor of the efflux pump promoter. In the pme $R$ mutant, $\mathrm{P}_{\text {mexab-oprm }}$ expressed at almost the same level in both the presence and absence of the inducer phloretin (Fig. 4B). The activity of $\mathrm{P}_{\text {pmeR }}$ in the pmeR-null strain also increased overall with respect to that achieved in the presence of the repressor (Fig. 4A and B) and was independent of the presence of phloretin. Also, a change in $\mathrm{P}_{\text {pmeR }}$ expression along the growth curve in DC3000R was observed because it gradually increased as the cultures approached the stationary growth phase (Fig. 4B and D). We considered the possibility that $\mathrm{P}_{p m e R}$ expression was RpoS dependent. However, no significant differences were observed in the expression of $\mathrm{P}_{p m e R}$ along the growth curve in an rpoS mutant compared with the wild type (not shown), suggesting that $\mathrm{P}_{\text {pmeR }}$ is not dependent on this $\sigma$ factor. We also studied the behavior of the $\mathrm{P}_{\text {mexAB-oprm }}$ and $\mathrm{P}_{\text {pmeR }}$ in DC3000A, a mutant lacking the efflux pump. We observed that the deletion of the efflux pump caused an increase of approximately twofold on the basal expression of $\mathrm{P}_{\text {mexAB-oprM }}$ compared with the activity in the wild-type strain, which persisted in the presence of phloretin, although more subtly (Fig. 4C). The same behavior was also observed in the expression of the pmeR promoter (Fig. 4C). The absence of the pump may account for the increased basal level of expression of both $\mathrm{P}_{\text {mexAB-oprM }}$ and $\mathrm{P}_{\text {pmeR }}$ in the DC3000A mutant, because accumulation of an unknown efflux pump substrate could act as inducer. Also, the increased level of expression of both $\mathrm{P}_{\text {mexAB-oprM }}$ and $\mathrm{P}_{\text {pmeR }}$ in the mexABoprM mutant in the presence of phloretin may be attributed to the accumulation of this compound within the cell due to the lack of the MexAB-OprM efflux pump.

In summary, the expression of both promoters in the strain DC3000R was found to be higher than that of the wild-type strain and similar to that observed in the presence of inducers as phloretin. These results further corroborate that PmeR represses not only the mexAB-oprM promoter activity but also its own expression.

The overexpression of the efflux pump in the pmeR-null mutant should cause a distinct phenotype (e.g., on its resistance to antimicrobial compounds). To confirm this hypothesis, we examined the susceptibility of the DC3000R mutant to several chemicals in comparison with the wild-type and DC3000A strains. For that, we determined the minimal inhibitory concentration (MIC) of different plant antimicrobial molecules, antibiotics, and biocides (Table 1). We observed that the pmeRnull mutant was more resistant than the wild type to several antibiotics such as ampicillin, carbenicillin, chloramphenicol, nalidixic acid, or tetracycline, whereas the DC3000A mutant was more sensitive than the wild type to those compounds, as had been previously shown (Stoitsova et al. 2008). Due to the low solubility of flavonoids in water, it was not possible to distinguish between the MIC of the wild type and the DC3000R mutant. Instead, we carried out antibiosis plate assays and determined the halo of growth inhibition caused by each compound. As a control, dimethyl sulfoxide (DMSO) was used in order to verify that the zone of inhibition was due to the flavonoid and not to the solvent, because DMSO had no effect on the growth of any of the strains. With this test, we observed that the strain deficient in the MexAB-OprM pump exhibited growth inhibition halos around (+)-catechin $(2.3 \mathrm{~cm})$, phloridzin $(1.97 \mathrm{~cm})$, and phloretin $(1.45 \mathrm{~cm})$ that were approximately twofold wider than those obtained with the wild type $(0.9,1$, and $0.75 \mathrm{~cm}$, respectively), suggesting that these flavonoids are substrates of the pump (Fig. 5). On the other hand, the mutant lacking the regulatory protein PmeR was more resistant than the wild type to (+)-catechin, and phloretin, with which
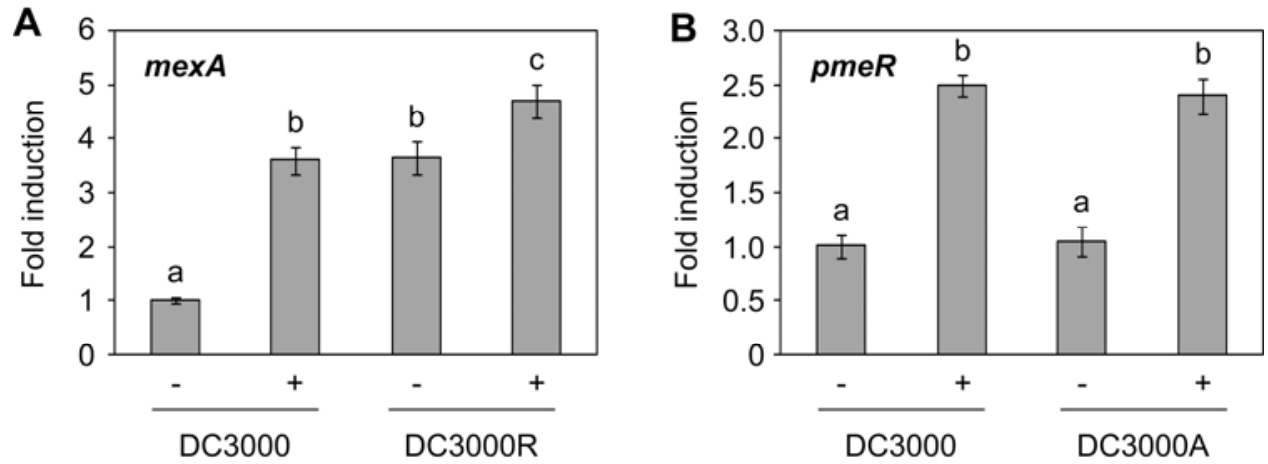

Fig. 3. Quantitative reverse-transcription polymerase chain reaction (RT-qPCR) of mexAB-oprM and pmeR RNA in different Pseudomonas syringae pv. tomato strains. DC3000, DC3000A, and DC3000R strains were grown in Luria-Bertani medium in the absence and in the presence of 0.3 mM phloretin ( $0.05 \mathrm{mM}$ for the DC3000A mutant). Samples were collected at an optical density at $660 \mathrm{~nm}$ of 1.5 , and total RNA was isolated and used to synthesized cDNA for RT-qPCR. Results shown are the means and standard deviations of three experiments with three replicates; a, b, and c denote analysis of variance categories for significant differences where $P<0.05$. 
no growth inhibition halos were observed (Fig. 5). This slight but reproducible increase in resistance to several antibiotics and other antimicrobial compounds that was observed in the pmeR-null mutant (Fig. 5; Table 1) is probably caused by the increased expression of the transporter due to its total derepression after the deletion of the repressor, and is in accordance with the higher basal level of $\mathrm{P}_{\text {mexAB-oprm }}$ expression observed in the mutant (Fig. 4B).

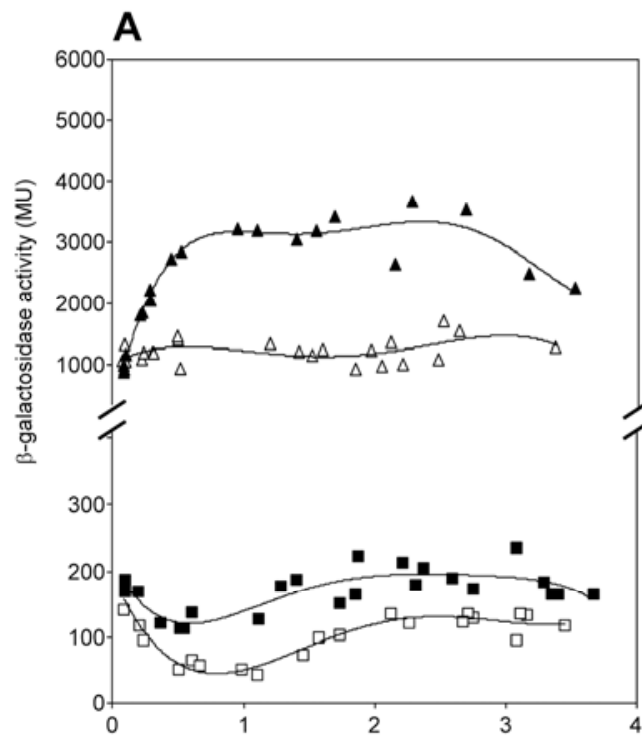

B
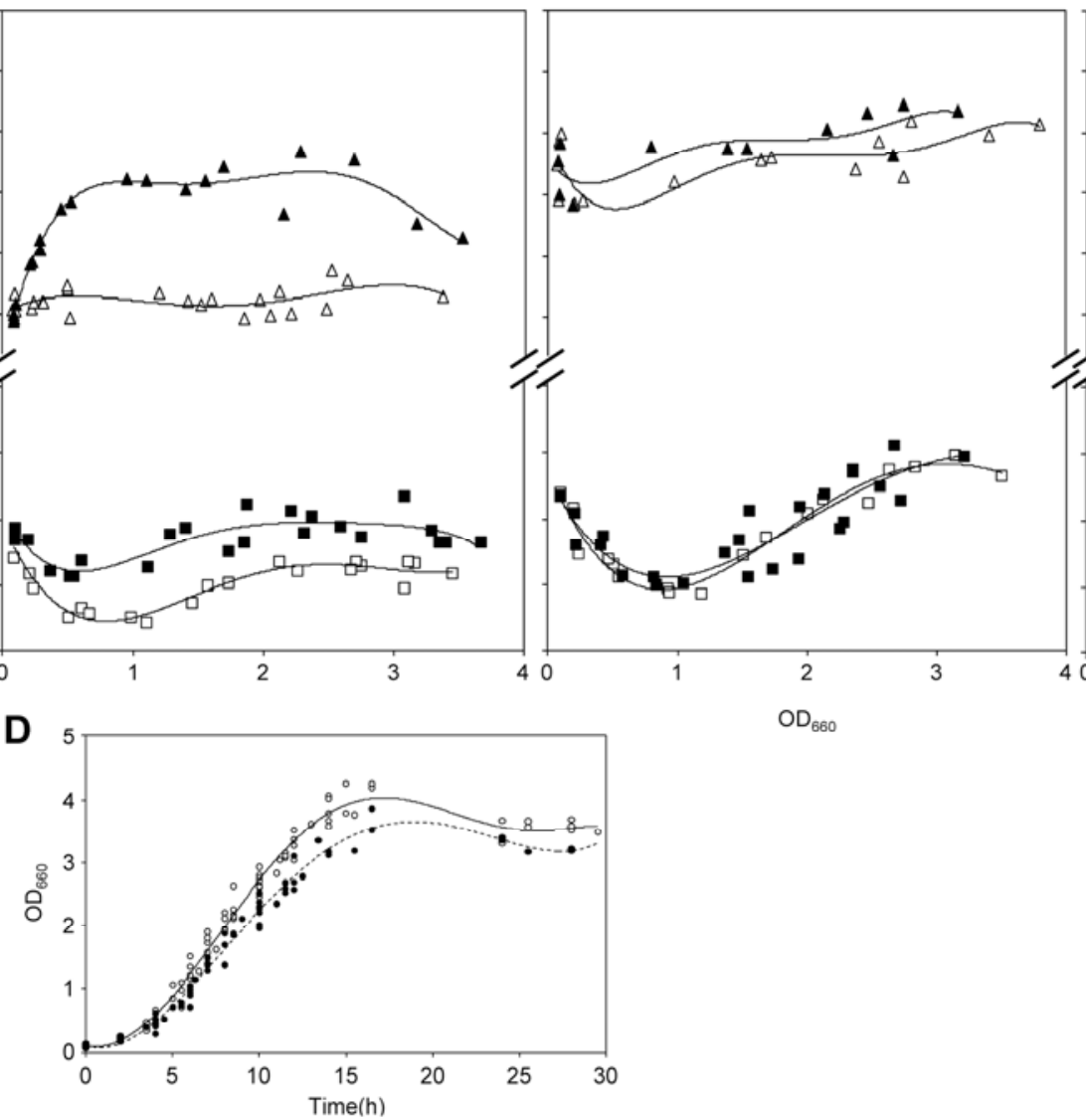

C

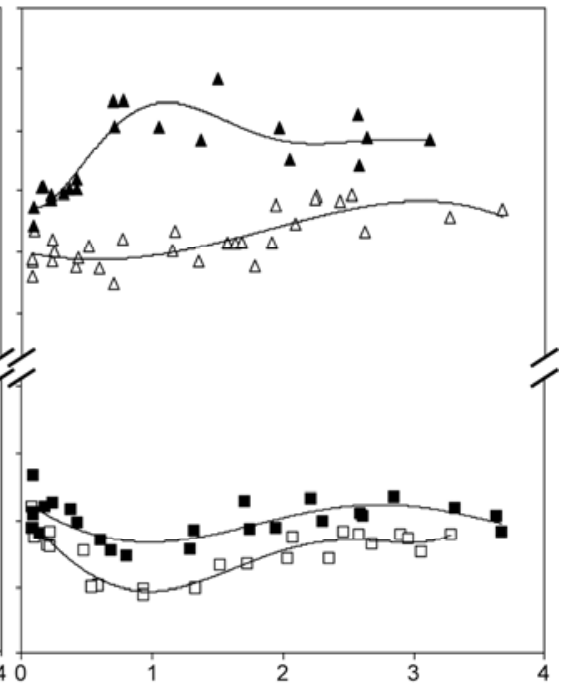

$\Delta \mathrm{P}_{\operatorname{mexA}}:$ 'lacZ -

口 $P_{\text {pmeR }}:$ 'lacZ -

$\Delta \mathrm{P}_{\operatorname{mex} A}:$ 'lacZ + phlo

Fig. 4. Expression of mexAB-oprM and pmeR promoters in Pseudomonas syringae pv. tomato DC3000, DC3000A, and DC3000R. $\beta$-Galactosidase activity from the mexAB-oprM (triangles) and pmeR (squares) promoters were determined in cultures grown in the absence (open symbols) or in the presence (filled symbols) of $0.3 \mathrm{mM}$ phloretin $(0.05 \mathrm{mM}$ for the DC3000A mutant). A, P. syringae pv. tomato DC3000; B, P. syringae pv. tomato DC3000R; C, P. syringae pv. tomato DC3000A; D, growth curve of DC3000 in the absence (open symbols) or in the presence (filled symbols) of $0.3 \mathrm{mM}$ phloretin. Other strains exhibited similar curves.

Table 1. Susceptibility of Pseudomonas syringae pv. tomato DC3000 and mutants to different antimicrobial agents

\begin{tabular}{|c|c|c|c|c|}
\hline \multirow[b]{2}{*}{ Compound } & \multicolumn{4}{|c|}{ Minimal inhibitory concentration $(\mu \mathrm{g} / \mathrm{ml})$} \\
\hline & DC3000 & DC3000A & DC3000R & DC3000R (pPV4R) $)^{\mathrm{a}}$ \\
\hline Ampicillin & 62 & 0.39 & 156 & ND \\
\hline Butylparaben & 759 & 379 & 1517 & 759 \\
\hline Carbenicillin & 128 & 0.5 & 512 & ND \\
\hline$(+)$-Catechin & $>9,072$ & 1,814 & $>9,072$ & $>9,072$ \\
\hline Cefotaxime & 7.8 & 0.08 & 62.5 & 7.8 \\
\hline Chloramphenicol & 3.1 & 0.39 & 12.5 & 3.1 \\
\hline Ethidium bromide & 78 & 20 & 156 & 78 \\
\hline Gentamicin & 0.5 & 0.5 & 0.5 & 0.5 \\
\hline Hesperetin & $>18,894$ & $>18,894$ & $>18,894$ & $>18,894$ \\
\hline Methylparaben & 594 & 297 & 1,188 & 594 \\
\hline Morin & $>9,447$ & 471 & $>9,447$ & $>9,447$ \\
\hline Nalidixic acid & 8 & 0.25 & 32 & 8 \\
\hline Naringenin & $>11,633$ & 582 & $>11,633$ & 11,633 \\
\hline Norfloxacin & 0.098 & 0.031 & 0.488 & 0.098 \\
\hline Phloretin & 8,571 & 857 & $>8,572$ & 4,286 \\
\hline Phloridzin & 29,528 & 3,691 & $>29,528$ & 7,382 \\
\hline Piperacillin & 1.56 & 0.039 & 3.12 & ND \\
\hline Quercetin & $>16,913$ & $>16,913$ & $>16,913$ & $>16,913$ \\
\hline Streptomycin & 1.50 & 1.50 & 1.50 & 1.50 \\
\hline Tetracycline & 0.50 & 0.05 & 2.00 & ND \\
\hline Triclosan & 0.98 & 0.98 & 0.98 & 0.98 \\
\hline
\end{tabular}

${ }^{\mathrm{a}} \mathrm{ND}=$ not determined. The plasmid used to complement carries resistance genes to those antibiotics. 
Heterologous complementation of the pmeR null mutant in trans with plasmid pPV4R, which carried the pmeR ORF from $P$. syringae pv. tomato $\mathrm{DC} 3000$, restored sensitivity to all antimicrobials tested (Table 1). This suggested that the regulator and the efflux pump have similar effector and substrate profiles, respectively. The level of resistance of the pmeR trans-complemented mutant was lower than that of the wildtype strain because it was more susceptible to phloridzin, phloretin, and naringenin, suggesting that there was a gene copy effect due to the presence of pmeR on a plasmid.

Previous results showed that deletion of MexAB-OprM resulted in increased susceptibility of $P$. syringae pv. tomato to several $\beta$-lactamic antibiotics (ampicillin, carbenicillin, and piperacillin) and some plant-produced antimicrobials (berberine, naringenin, and phloretin) (Stoitsova et al. 2008). Using the pmeR-deficient strain, we have defined new substrate specificities of the MexAB-OprM efflux pump after observing that resistance to several flavonoids was compromised in a strain lacking mexAB-oprM and increased in the pmeR-deficient strain (Fig. 5; Table 1). Therefore, butylparaben, (+)-catechin, cefotaxime, methylparaben, morin, and phloridzin seem to be substrates for the $P$. syringae pv. tomato MexAB-OprM transporter, which indicates that the MexAB-OprM pump removes antimicrobial compounds of very different natures and

A
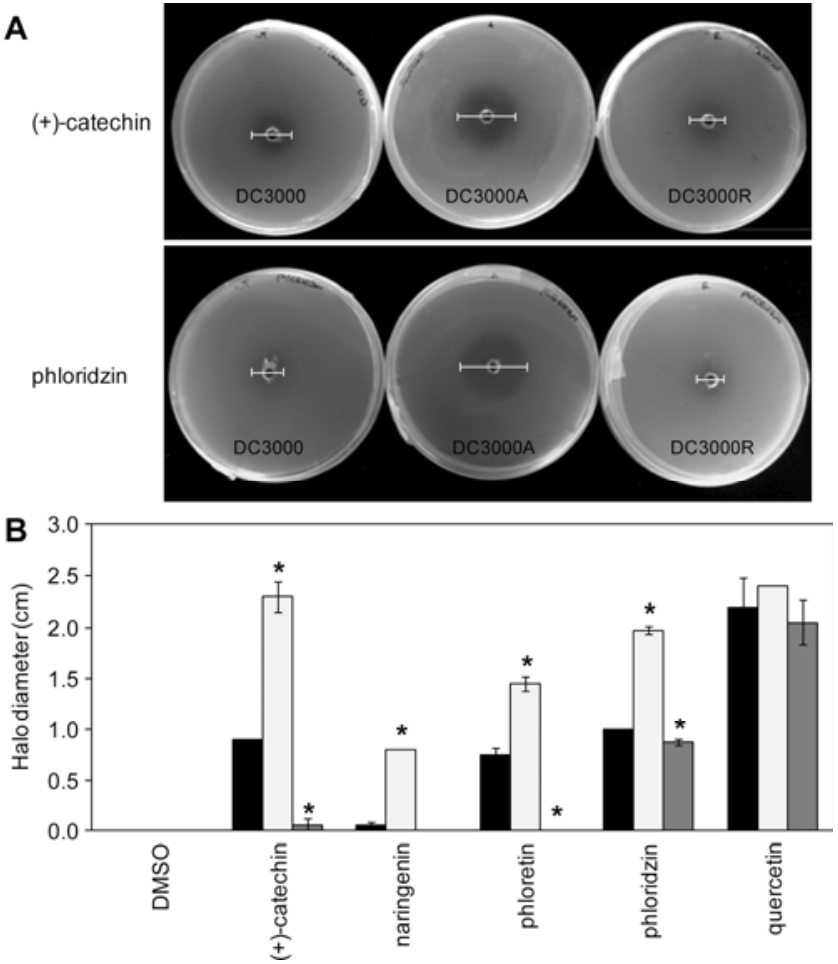

Fig. 5. Susceptibility of Pseudomonas syringae pv. tomato DC3000 to different flavonoids. Antibiosis assays were conducted with the strains DC3000, DC3000A, and DC3000R inoculated into the Luria-Bertani medium (1\% agar) to a final titer of $10^{6} \mathrm{CFU} / \mathrm{ml}$. Holes $(5 \mathrm{~mm}$ in diameter) were made and filled with $50 \mu \mathrm{l}$ of different flavonoid solutions. Final amounts of each compound were: (+)-catechin, $7.3 \mathrm{mg}$; morin, $7.6 \mathrm{mg}$; naringenin, $9.3 \mathrm{mg}$; phloretin, $6.9 \mathrm{mg}$; phloridzin, $11.8 \mathrm{mg}$; and quercetin, $8.5 \mathrm{mg}$. The growth inhibition halo was photographed and measured after incubation of the plates for $24 \mathrm{~h}$ at $26^{\circ} \mathrm{C}$. A, Plates of the antibiosis assay carried out with DC3000, DC3000A, and DC3000R in the presence of (+)catechin and phloridzin. The diameter of the halos is indicated. B, The inhibition halo obtained for DC3000 (black), DC3000A (white), and DC3000R (gray) in the presence of the control (dimethyl sulfoxide) and flavonoid solutions were measured (in triplicate), and the mean inhibition zone $(\mathrm{cm})$ calculated. Asterisks indicate that the differences with the wildtype strain are significant as determined by one-way analysis of variance $(P<0.05)$. chemical structures, conferring intrinsic resistance toward a broad range of antibiotics and other anti-bacterial agents of plant origin.

\section{PmeR acts a repressor of mexAB-oprM and pmeR expression by binding to their intergenic region.}

To prepare the PmeR protein for in vitro experiments, the pmeR gene was cloned in the vector pET-29a(+), and native PmeR was overproduced in Escherichia coli BL21(DE3) cells by means of isopropyl- $\beta$-D-thiogalactoside addition. Purification of PmeR almost to homogeneity was achieved by heparin affinity column chromatography followed by gel filtration column chromatography, as described below. On a sodium dodecyl sulfate polyacrylabide gel electrophoreses (PAGE) gel, a single 25.5-kDa protein was visualized (data not shown). As determined by gel filtration, the PmeR protein had a molecular mass of $54.4 \mathrm{kDa}$ (data not shown), indicating that PmeR is a dimer in solution.

DNase I footprinting analysis was performed to identify the PmeR binding site at the mexA and pmeR promoter regions. When the PmeR protein was mixed with the probe (a 263-bp fragment bearing the pmeR-mexA intergenic region, bases -169 to +74 , referred to the $\mathrm{P}_{\text {mexA }}$ ), PmeR protected a region of 28 bp against DNase I, from -38 to -11 at the mexA promoter and from -11 to +17 at its own promoter and transcription initiation site because both promoters partially overlap (Fig. 6A, lanes 2 and 4). This unique position of the PmeR binding site with respect both divergent promoter regions is consistent with the coregulation of these promoters observed in vivo.

The G nucleotides critical for PmeR binding to its operator were identified by dimethylsulfate (DMS) footprinting assays (Fig. 6B). In the top (mexA) strand, $\mathrm{G}-18$ and -22 were protected by PmeR binding, whereas $\mathrm{A}-10$ was hypermethylated. In the bottom (pmeR) strand, a greater number of nucleotides were important for DNA binding: $\mathrm{G}-12,+8,+5$, and +4 ; also, in this strand, A 18 was hypermethylated. The hypermethylation of As -10 and +18 may indicate that the DNA is distorted after PmeR binding. Our data support a model in which PmeR binds to its operator as two dimers and that union protects a region of $28 \mathrm{bp}$ containing two pseudopalindromic sequences (Fig. 6C). Probably, the union of the first PmeR homodimer to the operator region facilitates the binding of the second dimer. The overall structure of this DNA region, with two pseudopalindromic sequences, is similar to that of those members of the TetR family that bind DNA with a 4:1 stoichiometry (Schumacher et al. 2002).

\section{Structurally diverse substrates of MexAB-OprM inhibit binding of PmeR to its operator DNA.}

To quantitatively evaluate the PmeR binding to its operator site, we performed gel retardation assays using the PmeR protein and the same probe that was used for DNase I footprinting (Fig. 7). PmeR bound to the probe containing its binding site, which resulted in retarded bands on a PAGE gel depending on the PmeR concentration. The apparent dissociation constant of PmeR for its operator was estimated to be $7 \mathrm{nM}$ (Fig. 7A). It should be noted that only excess unlabeled intergenic competitor DNA and not excess control unspecific DNA was able to partially titrate out PmeR from its target DNA in gel mobility shift-binding reactions (not shown).

According to the footprint results, PmeR coordinately represses the expression of the efflux pump operon and its own expression by binding to an operator site which overlaps both promoters. From the in vivo experiments, we knew that mexAB-oprM and pmeR basal levels of expression exhibited a 3 - and 1.5-fold increase, respectively, in a pmeR-knockout mutant (Fig. 4). We expected that an increase in PmeR expression 
inhibited transcription from the mexAB-oprM and the pmeR promoters; however, we have shown that expression of both the efflux pump and PmeR were enhanced by the presence of certain chemicals (Fig. 2), which could only be achieved if the effectors that induce transcription from those promoters had a direct effect on PmeR repressor function. This prompted us to examine whether different efflux pump substrates showed inhibitory effects on the binding of PmeR to the cis sequences of mexAB-oprM and pmeR promoters in vitro (Fig. 7B). We performed electrophoretic mobility shift assays (EMSA) with the PmeR concentration fixed at $50 \mathrm{nM}$, a concentration that was sufficient to cause complete retardation of the probe (Fig. 7B). Three antibiotics (ampicillin, chloramphenicol, and tetracycline), two biocides (methyl and butyl paraben), and six flavonoids $((+)$-catechin, morin, naringenin, phloretin, phloridzin, and quercetin) were tested at $1 \mathrm{mM}$. We observed that all of
A

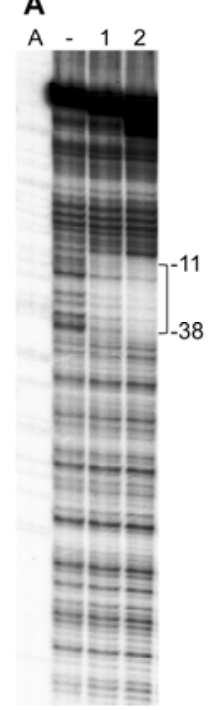

mexA strand

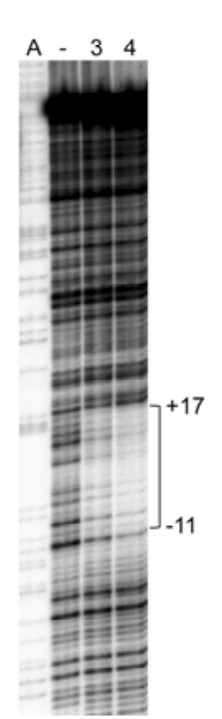

pmeR strand
B

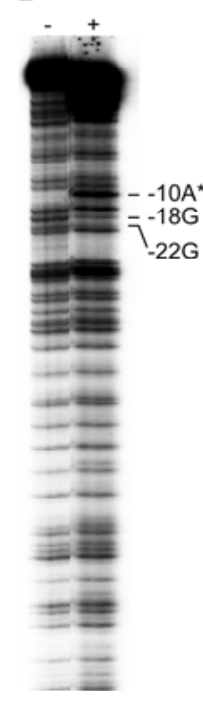

mexA strand
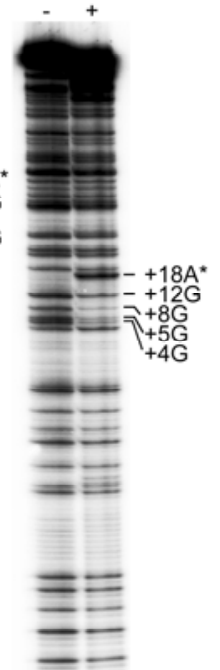

pmeR strand

\section{C}

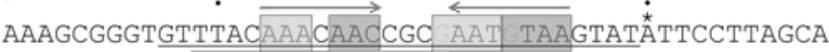
TTTCGCCCACAAAT TTT TT CGC $\underset{\star}{\longrightarrow}$ $\dot{p} \dot{p}_{\text {maxa }}$

Fig. 6. Binding of PmeR to its operator DNA. A, Identification of the PmeR binding site in the pmeR-mexA intergenic region by DNase I footprinting analysis. DNA probes corresponding to the pmeR-mexA intergenic region 5 '-end-labeled on either the top (mexA) or the bottom (pmeR) strand were prepared. The $5^{\prime}$-labeled probe $(20 \mathrm{nM})$ was incubated in the reaction mixture without (- lanes) and with the native PmeR protein $(0.5 \mu \mathrm{M}$, lanes 1 and 3; $1 \mu \mathrm{M}$, lanes 2 and 4). After partial digestion with DNase I, the DNAs were subjected to urea-polyacrylamide gel electrophoresis (PAGE). Lane A contained the products of the dideoxy sequencing reactions with the corresponding 5'-labeled primers. Nucleotide sequences protected by PmeR are indicated on the right of each panel. B, Identification of critical Gs for PmeR binding to its operator DNA by dimethylsulfate (DMS) footprint. DNA probes corresponding to the pmeR-mexA intergenic region $5^{\prime}$ end-labeled on either the top (mexA) or the bottom (pmeR) strand were prepared. The $5^{\prime}$-labeled probe $(20 \mathrm{nM})$ was incubated in the reaction mixture without (- lanes) and with the native PmeR protein $(1 \mu \mathrm{M},+$ lanes $)$. After treatment with DMS and piperidine, the resulting DNAs were subjected to urea-PAGE. G nucleotides protected by PmeR are indicated on the right of each panel and hyper-reactivity is also indicated (*). C, PmeRoperator DNA binding model. PmeR binds to a 28-bp region placed between positions -11 and -38 from the mexA transcriptional start site (underlined), as identified by DNAse I footprint assays. This operator DNA contains a pseudopalindromic sequence with two overlapping inverted repeats that can accommodate a pair of PmeR dimers each. Critical $\mathrm{G}$ nucleotides for PmeR binding are in gray. The pmeR transcription start site is indicated with an arrow. the flavonoids tested prevented PmeR binding to the probe, and the inhibitory effects of morin, naringenin, phloretin, and quercetin were prominent, whereas the effects of (+)-catechin and phloridzin were subtle. Also, clear inhibition of PmeR binding to the pmeR-mexA intergenic region was observed with butyl and methyl paraben. On the other hand, the antibiotics ampicillin, chloramphenicol, and tetracycline did not inhibit PmeR binding. Moreover, we observed that all the flavonoids that inhibited PmeR binding to the probe (morin, naringenin, phloretin, and quercetin) were able to disrupt the PmeR-DNA complex in vitro, releasing PmeR from its operator site (Fig. 7C). The in vitro gel retardation assay results essentially agreed with the results of the in vivo experiments (Figs. 2, 3, and 4) and indicate that the flavonoids morin, naringenin, phloretin, and quercetin and the biocides methyl and butylparaben have significant effects as modulators for PmeR, the repressor of the mexAB-oprM and pmeR genes.

\section{The PmeR/MexAB-OprM system contributes}

to the colonization of tomato plants by $P$. syringae pv. tomato.

Once we established the mode of action of PmeR, we studied whether the PmeR/MexAB-OprM system contributed to the pathogenic process of DC3000. For that, we compared the abilities of the wild-type $P$. syringae pv. tomato and DC3000A and DC3000R mutant strains to survive and multiply in tomato leaf tissues by monitoring bacterial populations and development of disease symptoms for 9 days after inoculation with bacteria at $10^{6} \mathrm{CFU} / \mathrm{ml}$ by spray. The starting populations of the three strains were similar (between $8.0 \times 10^{3}$ and $1.9 \times 10^{4}$ $\mathrm{CFU} / \mathrm{cm}^{2}$ ). The population size of $P$. syringae pv. tomato DC3000 and DC3000R reached a maximum of $2.5 \times 10^{7}$ $\mathrm{CFU} / \mathrm{cm}^{2}$ of leaf tissue on tomato, whereas population of the DC3000A mutant was 10 -fold lower $\left(2.3 \times 10^{6} \mathrm{CFU} / \mathrm{cm}^{2}\right)$. The growth rates of $P$. syringae pv. tomato DC3000 and DC3000A were already different at 2 days postinoculation (dpi) and, at 5 dpi, the population sizes of the wild type and the mutants started decreasing, albeit to different degrees (Fig. 8A).

The disease symptoms caused by the pmeR-null mutant were indistinguishable from those caused by the wild-type strain or the DC3000A mutant, which consisted of small water-soaked lesions surrounded by large regions of chlorosis that appeared 2 to 3 days after inoculation. These spots soon turned brown and the tissues surrounding the spots became yellow. However, and consistently with the lower population sizes, the symptoms caused by the DC3000A mutant were less abundant than those caused by $P$. syringae pv. tomato DC3000 and DC3000R strains and seemed to be retarded (Fig. 8B).

These results indicate that the loss of the MexAB-OprM transporter causes a decrease in the ability of $P$. syringae pv. tomato to colonize tomato host plants. However, the loss of PmeR had no detectable effect in the ability of the bacterium to colonize the plant and provoke symptoms.

\section{DISCUSSION}

Several roles have been proposed for the RND pumps. They could function as efflux systems for undesirable metabolic byproducts or they could play a more active role in cellular metabolism. The expression of these efflux pumps should then be controlled in response to specific physiological signals related to the role of the transporter in normal cell metabolism. Alternatively, they could be involved in the resistance to toxic compounds ordinarily present in the environment, produced by hosts or other microorganisms. Studies of several local transcriptional regulators have shown that they act by directly binding to a wide range of toxic compounds, similar to that exported by the membrane protein whose expression they 
control, thereby facilitating the induction of efflux pump genes in response to the presence of diverse toxic substances (Chuanchuen et al. 2002; Grkovic et al. 1998; Lomovskaya et al. 1995; Ma et al. 1996; Terán et al. 2003, 2006). However, the large majority of known pump substrates and regulator ligands are synthetic compounds, suggesting that further research is required to identify natural substrates and ligands for these proteins.

Stoitsova and associates (2008) and the results of this work show that the $P$. syringae pv. tomato DC3000 MexAB-OprM transporter has a broad substrate range, which confers resistance to multiple antibiotics ( $\beta$-lactams, cephalosporins, quinolones, tetracycline, and chloramphenicol), plant secondary metabolites (flavonoids such as berberine, $(+)$-catechin, morin, naringenin, phloridzin, and phloretin), or biocides (butylparaben and methylparaben, among others). This cross-resistance to antibiotics, biocides, and plant antimicrobial compounds has been observed in other bacteria (i.e., $P$. putida DOT-T1E TtgABC and KT2442 MepABC efflux pumps have been involved in multiple organic solvent and antibiotic resistance) (Fukumori et al. 1998; Ramos et al. 1998). In plant-pathogenic bacteria such as Erwinia amylovora and E. chrysanthemi, AcrAB-TolC transporter confers resistance to antibiotics, toxic compounds (such as crystal violet), and compounds derived from plants such as phloretin and naringenin (Burse et al. 2004; Maggiorani-Valecillos et al. 2006).

In this study, we have analyzed the expression of the mexAB-oprM efflux pump operon and the regulatory gene pmeR at the transcriptional level and investigated the role of the PmeR protein in this process. We observed that mex $A B$ oprM and pmeR were expressed in vivo at a relatively high and moderate basal level, respectively, and that addition of the structurally dissimilar chemicals (butyl and methylparaben, or flavonoids such as phloretin and naringenin), which are also substrates of the MexAB-OprM transporter, resulted in derepression of the mexAB-oprM and pmeR promoters in vivo (Figs.
2, 3, 4, and 7). We demonstrate that the antimicrobial-dependent induction of the $P$. syringae pv. tomato multidrug efflux pump MexAB-OprM and its regulatory gene, $p m e R$, is mainly controlled by the repressor protein PmeR (Figs. 3, 4, 6, and 7), although we cannot discard the involvement of other regula-

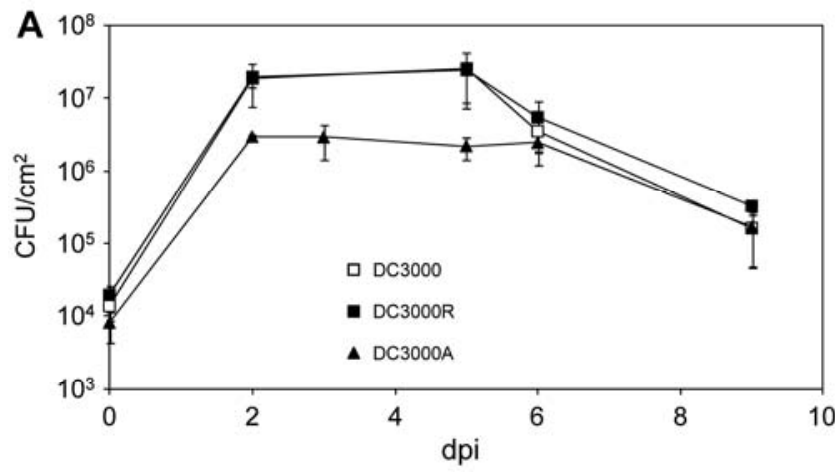

B
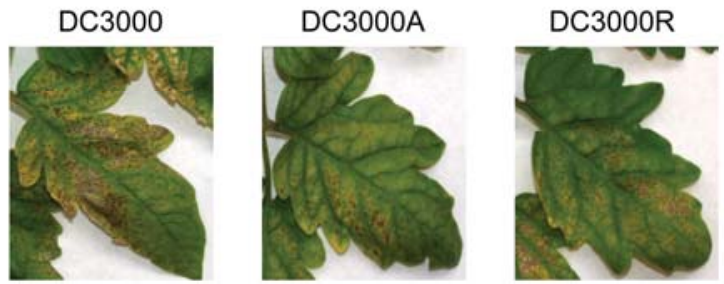

Fig. 8. Bacterial growth and symptom development on tomato leaves. A, Time course of in planta growth of different Pseudomonas syringae pv. tomato strains: DC3000, DC3000A, and DC3000R. Development of CFU on the primary leaves of tomato plants at $0,2,3,5,6$, and 9 days after artificial inoculation with approximately $10^{6} \mathrm{CFU} / \mathrm{ml}$ by spray. Data represent the average of four experiments \pm standard error. B, Development of symptoms induced on primary leaves of tomato plants at 9 days after artificial inoculation with P. syringae pv. tomato DC3000 (wild type) and DC3000R and DC3000A mutants at $10^{6} \mathrm{CFU} / \mathrm{ml}$ by spray.
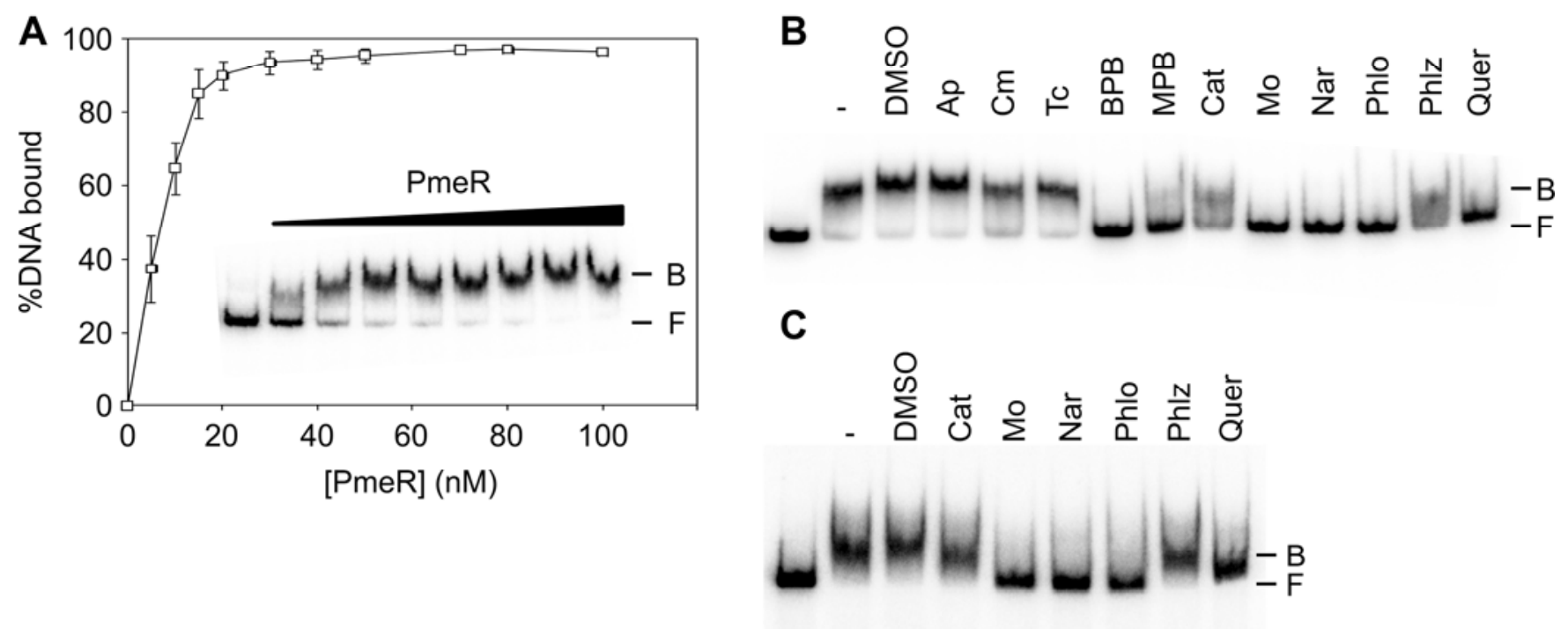

Fig. 7. A, In vitro binding affinity of PmeR to the pmeR-mexA intergenic region. The 263-pb fragment containing the $p m e R$-mexAB-oprM intergenic region $(1 \mathrm{nM})$ was incubated without protein or with increasing concentrations of native PmeR, which increased the percentage of DNA bound. Results shown in the graphic are the mean of four different experiments with standard deviations. Representative electrophoretic mobility shift assays (EMSA) are also shown in the figure (lane 1, without protein; lanes 2 to 9 with 5, 10, 15, 20, 30, 40, 50, and 80 nM native PmeR). B, Evaluation of the inhibitory effect of flavonoids on PmeR binding to the pmeR-mexA intergenic region by gel retardation. The ${ }^{32} \mathrm{P}$-labeled probe (1 nM) was incubated without protein (lane 1$)$ and with 50 $\mathrm{nM}$ PmeR (lanes 2 to 14) in the absence (lane 2) or in the presence of $1 \mathrm{mM}$ of the following effectors: (+)-catechin (Cat), morin (Mo), naringenin (Nar), phloretin (Phlo), phloridzin (Phlz), quercetin (Quer), ampicillin (Ap), chloramphenicol (Cm), tetracycline (Tc), butylparaben (BPB), and methylparaben (MPB). Experiments were repeated three times with similar outcome and the results of representative experiments are shown. C, Effect of flavonoids on the PmeR-DNA complex. EMSAs were carried out as above, with the only difference that the effectors were added 10 min after the incubation of PmeR with the probe. 
tory proteins, including global regulators, given that the addition of phloretin slightly increased expression of mexA in the PmeR-deficient mutant (Figs. 3 and 4). By both in vitro EMSA (Fig. 7) and DNase I and DMS protection (Fig. 6) experiments, we have identified the operator site for PmeR in the pmeR-mexA intergenic region and have shown that PmeR is released from its operator DNA site by binding to the same compounds that induce expression in vivo (Figs. 2, 3, 4, and 7). PmeR is a member of the TetR family of transcriptional regulators, all of which share a highly homologous N-terminal DNA-binding domain with a helix-turn-helix motif and other conserved sequence signatures (Ramos et al. 2005). We propose that PmeR, similar to most characterized regulators of the TetR family, represses transcription through operator binding mediated by its $\mathrm{N}$-terminal domain, and this repression is relieved by binding of structurally dissimilar molecules to their C-terminal ligand-binding and dimerization domain. However, within the TetR family members, there are proteins which bind to 11-bp operator sites, such as EF0787, and others, such as CgmR or QacR, which bind to longer (30- and 26-bp, respectively) operators (Yu et al. 2010). PmeR binds to an imperfect inverted repeat operator sequence which overlaps the mex $A B$ oprM and pmeR promoters, specifically with the -10 region of the pme $R$ promoter and its transcription start site, and the -35 region of the mexAB-oprM promoter. This operator site comprises 11-bp half sites and has a complex symmetry, with two possible overlapping pseudopalindromic sequences (Fig. 6). This unique position of the PmeR binding site with respect to both divergent promoter regions is consistent with the coregulation of these promoters observed in vivo.

Based on all the evidence obtained in this work, we propose a model for PmeR binding to its operator DNA similar to that described for QacR (Schumacher et al. 2002) (i.e., the cooperative binding of two PmeR dimers to a 28-bp pseudopalindrome operator DNA sequence). In this model, each half site would receive two monomers belonging to different dimers (Fig. 6C). Hence, the PmeR repressor may hinder access of RNA polymerase to mexAB-oprM and pmeR promoters in the same way that TetR inhibits expression from its cognate promoters (Orth et al. 2000). Furthermore, the location of the operator site with respect to the promoters and transcription initiation sites of mexAB-oprM and pmeR explains why $\mathrm{P}_{\text {mexAB- }}$ ${ }_{\text {opr } M}$ is expressed in vivo at a relatively high level, whereas the $\mathrm{P}_{\text {pmeR }}$ basal level is lower, and how PmeR adjusts its own levels of expression in response to the different types and concentrations of effectors (Figs. 2 and 7). The repression of mexABoprM and pmeR transcription by PmeR could be overcome by the addition of butyl and methylparaben, morin, naringenin, phloretin, and quercetin, resulting in the induction of mexABoprM and pmeR expression (Figs. 2 and 7). Those structurally unrelated molecules activate pump expression by binding to free PmeR and inhibiting its binding to its operator site or to the PmeR-DNA complex and releasing PmeR from its operator site, therefore allowing transcription to initiate. Direct recognition of structurally dissimilar compounds rather than the involvement of a secondary messenger appears to be a common feature in bacterial multidrug transporter regulation by TetR regulators (Yu et al. 2010). Based on the structural studies, it has been established that the remarkable ability of those proteins to recognize a structural diversity of compounds is enabled by a voluminous multisite ligand-binding pocket, which comprises distinct and overlapping subpockets (Alguel et al. 2007; Brooks et al. 2007; Madoori et al. 2009; Murray et al. 2004; Schumacher et al. 2001, 2004). Overall, the results show that both $P$. syringae pv. tomato DC3000 RND transporter MexAB-OprM and its cognate repressor PmeR possess multidrug recognition properties. PmeR functions as a mul- tidrug-binding regulator that specifically modulates its own expression and the expression of the mexAB-oprM efflux pump in response to the presence of different antimicrobials, some of which are substrates of the transporter. In this regard, it is important to highlight that the effector profile of PmeR is narrower than the substrate range of MexAB-OprM, which means that pump expression is induced only in the presence of some of the compounds that it can expel. The broad substrate specificity of this transporter is an evolutionary adaption of the bacteria to survive in different environments. However, the large majority of known pump substrates and regulator ligands are synthetic compounds, some of which are unlikely to be found in the natural habitat of the bacteria. Therefore, plant compounds or metabolites from other bacteria may be the natural substrates or ligands present in $P$. syringae pv. tomato habitat, and synthetic compounds expelled by the pumps (or recognized by the regulators) resemble the intended substrates.

We have identified compounds produced by plants that can act as effectors of the regulatory protein and substrates of the efflux pump. Moreover, some plant signal molecules such as phloretin and naringenin can significantly promote mex $A B$ oprM and pmeR gene expression, reaching levels of induction up to 2.5 and 2 times, respectively (Fig. 2). Because the expression of MexAB-OprM increases in the presence of plant antimicrobials, which would greatly reduce the effect of these plant products on initial bacteria-plant interactions, we thought that mutants overexpressing the MDR efflux pump would exhibit increased survival or colonization rates. For this purpose, we carried out infection assays with knock-out mutants on the regulator and the efflux pump to study colonization and virulence in susceptible plants, observing that the disruption of pmeR had no significant effect on virulence or colonization of the host plant (Fig. 8). However, the disruption of mexAB-oprM, the efflux pump structural genes, did result in a decreased ability of the bacteria to colonize the host plant (Fig. 8).

For decades of medical research, flavonoids have been reported to possess numerous useful properties, including antimicrobial activity. The antibacterial mechanisms of action of several flavonoids have been elucidated and shown to act on multiple cellular targets (Cushnie and Lamb 2005). The first demonstrated target was DNA gyrase (Ohemeng et al. 1993) and the relevant inhibition mechanism by quercetin was proposed to be through two parallel means. One is the binding of quercetin to DNA through hydrophobic interactions and the other is related to its competition with ATP for the substrate binding site of the gyrase (Papler et al. 2003). Although knowledge about the antibacterial action of various flavonoids is accumulating, little is known about how the bacteria specifically react to those plant products and how this response is integrated into the cell regulatory circuits. We have characterized one mechanism of bacterial resistance to different flavonoids in the plant pathogen $P$. syringae pv. tomato DC3000, the MDR efflux pump MexAB-OprM. Flavonoids are the best substrates of MexAB-OprM and the best inducers of its expression at a transcriptional level. MexAB-OprM has been shown to be involved in tolerance to a broad range of compounds and in the ability to multiply in planta (Stoitsova et al. 2008; this work). Therefore, we propose that our model MexAB-OprM efflux pump from $P$. syringae pv. tomato DC3000 mediates resistance to antimicrobial compounds produced by plants, conferring protection that facilitates the initial survival in its ecological niche, the leaf surface; subsequent colonization of the host; and disease. Additionally, MexABOprM is able to remove other antimicrobial agents, such as antibiotics, which could allow $P$. syringae pv. tomato DC3000 to compete effectively against other epiphytic bacteria found in 
leaves. In this sense, we have shown that there is a common pathway for the response to structurally and functionally different antimicrobial compounds: antibiotics, biocides, and plant secondary products such as flavonoids.

\section{MATERIALS AND METHODS}

Bacterial strains, plasmids, and culture medium.

The bacterial strains and plasmids used in this study are shown in Table 2. P. syringae pv. tomato DC3000 (Cuppels 1986) and mutants were routinely grown in Luria-Bertani (LB) medium (Sambrook et al. 1989) at $28^{\circ} \mathrm{C}$. When required, the following antibiotics were added to the cultures or plates to reach final concentrations of $10 \mu \mathrm{g} / \mathrm{ml}$ for rifampicin, $10 \mu \mathrm{g} / \mathrm{ml}$ for tetracycline, $25 \mu \mathrm{g} / \mathrm{ml}$ for kanamycin, and $100 \mu \mathrm{g} / \mathrm{ml}$ for ampicillin.

We constructed fusions of the promoters of the mexABoprM operon and pmeR gene promoter to a promoterless $l a c Z$ gene in the low-copy-number (two to four copies per cell) pMP220 vector (Spaink et al. 1987). The pmeR-mexA intergenic region (254 bp) was amplified by PCR from $P$. syringae pv. tomato DC3000 chromosomal DNA, which was isolated with Wizard Genomic, DNA purification kit (Promega Corp., Madison, WI, U.S.A.), with primers incorporating EcoRI and PstI restriction sites-EcoRI-PmexA1 (5'-AAAAGAATTCGA CCTCAAAAGATTC- $3^{\prime}$ ) and PmexA-PstI2 (5'-AAAACTGC AGCCTCGGGGCAGG' $-3^{\prime}$ )— to create a fusion of the mexABoprM promoter to 'lacZ; and with primers PstI-PpmeR1 (5'AAAACTGCAGAAGACCTCAAAAGATTC-3') and PpmeREcoRI2 (5'-AAAAGAATTCCTCGGGGCAGG-3') to create a fusion of the pmeR promoter to 'lacZ. Upon amplification, DNA was digested with EcoRI and PstI and ligated to EcoRIPstI-digested pMP220 to produce pPV1A $\left(\mathrm{P}_{\text {mexA }}:: l a c Z\right)$ and pPV2R $\left(\mathrm{P}_{\text {pme }}:\right.$ :lacZ). Plasmids pPV1A and pPV2R were sequenced to make sure that no mutations were introduced in the corresponding promoter regions. These plasmids were electroporated into $P$. syringae pv. tomato DC3000 or its derivative mutants as described by Enderle and Farwell (1998). Cells in 0.2 -cm cuvettes were submitted to a high-voltage pulse $(1,800$ V) for $5 \mathrm{~ms}$ by using a MicroPulser electroporation apparatus (Bio-Rad, Hercules, CA, U.S.A.), and transformants were selected in LB agar plates supplemented with tetracycline.
We constructed a plasmid bearing the pmeR gene for heterologous complementation of the respective deficient mutant. A fragment including the pmeR gene was amplified by PCR from $P$. syringae pv. tomato DC3000 chromosomal DNA using extPmeR_F (5'-TGAACCGCGCTTGCGCTCAT-3') and PpmeR-EcoRI.2 (5'-AAAAGAATTCCTCGGGGCAGG-3') oligonucleotides. This DNA was cloned into pCR-XL-TOPO vector (Invitrogen Corp., Carlsbad, CA, U.S.A.) and sequenced. After digestion with EcoRI, the fragment was ligated to EcoRIdigested pJB3Tc19. The resulting plasmid, pPV4R, carried a $1.36-\mathrm{kb}$ fragment with the pmeR gen from $P$. syringae pv. tomato DC3000.

\section{Construction of a pmeR and mexA-null mutants of $P$. syringae pv. tomato $\mathrm{DC} 3000$.}

We constructed the pmeR-null mutant (DC3000R) by gene replacement, for which we first knocked out the pmeR gene in vitro. Plasmid pPVG-R is a pGEM-T (Promega Corp., Madison, WI, U.S.A.) derivative that carries a 1,805-bp fragment harboring the pmeR gene and flanking DNA. This plasmid bears an artificial EcoRI site around the middle of the pmeR ORF. Upon digestion with EcoRI, the plasmid was ligated to a $2.25-\mathrm{kb}$ fragment bearing the $\Omega \mathrm{Km}$ interposon from

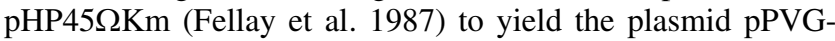
$\mathrm{R} \Omega \mathrm{Km}$, which was used for in vivo gene replacement. The suicide plasmid pPVG-R $\Omega \mathrm{Km}$ encodes resistance to ampicillin (Ap) and kanamycin $(\mathrm{Km})$ and was electroporated into $P$. syringae pv. tomato DC3000 (Enderle and Farwell 1998). Transformants that had acquired the inactivated gene (Km resistant $\left.\left[\mathrm{Km}^{\mathrm{r}}\right]\right)$ were selected. Among the $\mathrm{Km}^{\mathrm{r}}$ clones, we searched for Ap $(250 \mu \mathrm{g} / \mathrm{ml})$-sensitive $\left(\mathrm{Ap}^{\mathrm{s}}\right)$ ones, which were expected to be the result of a double-recombination event. One of the $\mathrm{Km}^{\mathrm{r}} / \mathrm{Ap}^{\mathrm{r}}$ clones, called DC3000R, was chosen and confirmed by Southern blot to have the wild-type $p m e R$ gene replaced by the mutant allele pmeR:: $\Omega K m$ (not shown).

A mexA-null mutant (DC3000A) selectable with antibiotic $(\mathrm{Km})$ was also constructed by gene replacement. We first constructed the plasmid pPVG-A, a pMBL (Dominion, Madrid) derivate bearing a 2,106-bp fragment with the mexA gene and flanking DNA. The plasmid was digested with Eco47III (approximately $440 \mathrm{bp}$ after the mexA first ATG) and ligated to the $\Omega \mathrm{Km}$ interposon (with added Eco47III sites in both ends)

Table 2. Bacterial strains and plasmids

\begin{tabular}{|c|c|c|}
\hline Strain, plasmid & Genotype & Reference \\
\hline \multicolumn{3}{|l|}{ Strains } \\
\hline \multicolumn{3}{|c|}{ Pseudomonas syringae pv. tomato } \\
\hline DC3000 & Rif $^{r}$ & Cuppels 1986 \\
\hline DC3000R & $\mathrm{Km}^{\mathrm{r}}, p m e R:: \Omega \mathrm{Km}$ & This work \\
\hline DC3000A & $\mathrm{Km}^{\mathrm{r}}$, mexA:: $\Omega \mathrm{Km}$ & This work \\
\hline \multicolumn{3}{|l|}{ Escherichia coli } \\
\hline B834(DE3) & $\mathrm{F}^{-}$, ompT hsd $S_{B}\left(\mathrm{r}_{\mathrm{B}}{ }^{-} \mathrm{m}_{\mathrm{B}}^{-}\right)$gal dcm met & Novagen \\
\hline \multicolumn{3}{|l|}{ Plasmids } \\
\hline pET29a(+) & $\mathrm{Km}^{\mathrm{r}}$, protein expression vector & Novagen \\
\hline pCR-XL-TOPO & $\mathrm{Km}^{\mathrm{r}}$, cloning vector & Invitrogen Corp. \\
\hline pGEM-T & $\mathrm{Ap}^{\mathrm{r}}, \mathrm{T} / \mathrm{A}$ cloning vector & Promega Corp. \\
\hline $\mathrm{pHP} 45 \Omega \mathrm{Km}$ & $\mathrm{Ap}^{\mathrm{r}}$, carries the $2.25-\mathrm{kb} \Omega \mathrm{Km}$ interposon & Fellay et al. 1987 \\
\hline pJB3Tc19 & $\mathrm{Ap}^{\mathrm{r}}, \mathrm{Tc}^{\mathrm{r}}$, cloning vector, $\mathrm{P}_{l a c}$ promoter & Blatny et al. 1997 \\
\hline pMP220 & $\mathrm{Tc}^{\mathrm{r}},{ }^{\prime} l a c Z$ promoter probe plasmid & Spaink et al.1987 \\
\hline pMBL & $\mathrm{Ap}^{\mathrm{r}}, \mathrm{T} / \mathrm{A}$-cloning vector & Dominion-MBL \\
\hline pPV1A & $\mathrm{Tc}^{\mathrm{r}}$, pMP220 bearing mexAB-oprM promoter region & This work \\
\hline $\mathrm{pPV} 2 \mathrm{R}$ & $\mathrm{Tc}^{\mathrm{r}}$, pMP220 bearing pmeR promoter region & This work \\
\hline pPV3 & $\mathrm{Km}^{\mathrm{r}}$, pET29a(+) derivative vector used to produce native PmeR & This work \\
\hline pPV4R & pJB3Tc19::pmeR & This work \\
\hline pPVG-R & $\mathrm{Ap}^{\mathrm{r}}, 1,805-\mathrm{bp}$ chromosomal fragment bearing pmeR cloned into pGEM-T & This work \\
\hline pPVG-R $\Omega K m$ & pPVG-R with $\Omega \mathrm{Km}$ inserted into the EcoRI site & This work \\
\hline pPVG-A & $\mathrm{Ap}^{\mathrm{r}}, 2,106-\mathrm{bp}$ chromosomal fragment bearing mexA cloned into pMBL & This work \\
\hline pPVG-A $\Omega$ Km & pPVG-A with $\Omega \mathrm{Km}$ inserted into the Eco47III site & This work \\
\hline
\end{tabular}

${ }^{\mathrm{a}} \mathrm{Rif}^{\mathrm{r}}, \mathrm{Km}^{\mathrm{r}}, \mathrm{Ap}^{\mathrm{r}}$, and $\mathrm{Tc}^{\mathrm{r}}$ stand for resistance to rifampicin, kanamycin, ampicillin, and tetracycline, respectively. 
to yield the plasmid pPVG-A $\Omega \mathrm{Km}$, which was used for in vivo gene replacement. The selection and check up of the mexA:: $\Omega K m$ mutant was as above. Given the polar effect of the $\Omega K m$ insertion, this mutant was, in fact, an mexAB-oprM-null mutant.

\section{Preparation of mRNA.}

P. syringae pv. tomato DC3000, DC3000R, and DC3000A were grown overnight in LB medium supplemented with the appropriate antibiotics at $28^{\circ} \mathrm{C}$. Cells were then diluted to an initial optical density at $660 \mathrm{~nm}\left(\mathrm{OD}_{660}\right)$ of 0.1 and incubated with shaking at $28^{\circ} \mathrm{C}$ in the absence or in the presence of sublethal concentrations of phloretin $(0.3 \mathrm{mM}$ for DC3000 and DC3000R and $0.05 \mathrm{mM}$ for the DC3000A). The cells were pelleted at different $\mathrm{OD}_{660}$ values, depending on the experiment, and were processed for RNA isolation using TRI Reagent LS (Molecular Research Center, Cincinnati, OH, U.S.A.) according to the manufacturer's instructions, except that the TRI Reagent was preheated at $70^{\circ} \mathrm{C}$ and the lysis step was carried out at $65^{\circ} \mathrm{C}$. The RNA obtained was treated with RNasefree DNase I (Qiagen, Hilden, Germany) followed by purification with an RNeasy mini kit (Qiagen). RNA concentration was determined spectrophotometrically and its integrity was assessed by agarose gel electrophoresis.

\section{Primer extension analysis.}

mRNAs of the mexAB-oprM pump operon and the pmeR regulator were reverse transcribed with SuperScript III (Invitrogen) using a specific oligonucleotide primer complementary to a sequence located 107 to 126 nucleotides from the transcription start point of each gene (PEmexA1 [5'-GAACGGT AACAGCTGGCTTG-3'] and PEpmeR_IR [5'-ATGCATCTG GTGCATGCC-3'] for mexAB-oprM and pmeR, respectively). Oligonucleotides were end-labeled with $\left[\gamma^{32} \mathrm{P}\right] \mathrm{ATP}$ and T4 polynucleotide kinase, and 0.5 to 1 pmol was annealed to 20 $\mu \mathrm{g}$ (for mexAB-oprM) or $30 \mu \mathrm{g}$ (for pmeR) of total RNA for 5 min at $90^{\circ} \mathrm{C}$, followed by $5 \mathrm{~min}$ at $65^{\circ} \mathrm{C}$. cDNA was synthesized by using SuperScript III $\left(2 \mathrm{~h}\right.$ at $\left.58^{\circ} \mathrm{C}\right)$ and analyzed in urea-polyacrylamide sequencing gels. The obtained cDNA bands were visualized by using a Phophorimager system (Personal FX equipment; Bio-Rad).

\section{Quantitative RT-PCR assay.}

Total RNA $(1 \mu \mathrm{g})$ treated with RNase-free DNase I Set (Qiagen) was retrotranscribed to cDNA with SuperScript II reverse transcriptase (Invitrogen) using random hexamers as primers. The lack of genomic DNA contamination was checked by PCR amplification of RNA samples without prior cDNA synthesis. The specific primer pairs used to amplify cDNA were 5'-CAGGACGACCGCTTTCCGTGTGG-3' and 5'-CCTTGGCACTGTTGGCGTTGGCTTC-3' for mexA, 5'CGGCAAGGGTCGCAATGTCAGC-3' and 5'-TCGCACCA AAGAGGAAGCTCAGATCACC-3' for pmeR, and 5'-GGCA AGGTCACCCGCTTCAAGGAAT-3' and 5'-GACCGCCACG CTTGTACTCAGGGAAC-3' for gyrA. Primer efficiency was determined as in Michán and Pueyo (2009) and was optimal $(\approx 100 \%)$ for all the pairs. Real-time RT-PCRs were performed in triplicate. No primer dimers were detected. Real-time PCR conditions were as detailed in Michán and Pueyo (2009): each $25-\mu$ reaction contained $50 \mathrm{ng}$ of the target cDNA, $300 \mathrm{nM}$ each primer, and iQ SyBrGreen Supermix (Bio-Rad). Following PCR, melt-curve analysis was performed to confirm the specificity of the amplification reaction. Relative transcript abundance was calculated using the $\Delta \Delta$ cycle threshold $(\mathrm{Ct})$ method (Livak and Schmittgen 2001). P. syringae pv. tomato transcriptional data were normalized to the housekeeping gene gyrA. The expression of a given gene relative to gyrA was calculated as the difference in quantitative PCR threshold cycles
$(\Delta \mathrm{Ct}=$ Ctgene of interest - CtgyrA $)$. The expression of each gene was determined with the control treatment (wild type in the absence of phloretin) as the difference between $\Delta \mathrm{Ct}$ values $(\Delta \Delta \mathrm{Ct})$. One PCR cycle represents a twofold difference in template abundance; therefore, fold-change values are calculated as $2^{-\Delta \Delta \mathrm{Ct}}$.

\section{$\beta$-gal assays.}

Bacterial cells were inoculated from fresh LB agar plates that had been supplemented with the appropriate antibiotics and in which the bacteria were allowed to grow overnight at $28^{\circ} \mathrm{C}$. Cultures were diluted to an initial $\mathrm{OD}_{660}$ of 0.1 in the same medium supplemented or not with the chemicals to be tested and were then incubated at $28^{\circ} \mathrm{C}$ with shaking. The compounds tested in the $\beta$-gal assays were usually added between 0.08 and $1 \mathrm{mM}$ (sublethal concentrations), and were dissolved in DMSO when needed (note that the latter did not interfere with the induction assays in this study). $\beta$-Gal activity was determined in triplicate in permeabilized cells along the growth curve or when cultures reached an $\mathrm{OD}_{660}$ of 2 (Miller 1972). Results are the mean of at least five different experiments.

\section{Antimicrobial agent susceptibility tests.}

The MIC of the tested compounds was determined in LB medium by the microtiter broth dilution method (Amsterdam 1991). Microtiter plate wells containing each $100 \mu \mathrm{l}$ of LB were inoculated with $10^{6} \mathrm{CFU} / \mathrm{ml}$ and incubated for $24 \mathrm{~h}$ at $28^{\circ} \mathrm{C}$. The growth was then analyzed and the MIC corresponded to the minimal concentration at which growth was inhibited by at least $90 \%$.

Antibiosis assays were conducted on plates with the bacterial strains grown to a $\mathrm{OD}_{660}$ of 1 (approximately $10^{8} \mathrm{CFU} / \mathrm{ml}$ ), which were then inoculated into the LB (1\% agar) to a final title of $10^{6} \mathrm{CFU} / \mathrm{ml}$ before laying the plates. Holes $(5 \mathrm{~mm}$ in diameter) were punched into each plate by a cork borer and filled with $50 \mu \mathrm{l}$ of different flavonoid solutions (in DMSO). After $24 \mathrm{~h}$ of incubation at $26^{\circ} \mathrm{C}$, the plates were monitored for zones of growth inhibition in the bacterial lawn.

\section{Overexpression and purification of PmeR.}

A 672-bp fragment containing the $p m e R$ gene was amplified from $P$. syringae pv. tomato DC3000 chromosomal DNA by PCR with primers 5-pmeR_Pto (5'-AAAAAACATATGGTCC GTCGAACCAAAG-3') and 3-pmeR_Pto (5'-aaaaaaAAGCTT TCATCATAACCTTTCACG-3'), which generated NdeI and HindIII restriction sites, respectively (underlined), and the latest also included two stop codons (in bold). The PCR products were restricted with the above enzymes and subsequently ligated into the pET29a $(+)$ vector (NovagenEMD Chemicals Inc, Gibbstown, NJ, U.S.A.) previously digested with NdeI and HindIII. The resulting plasmid was termed pPV3.

For the purification of native PmeR, pPV3 was transformed into Escherichia coli B834(DE3). The cells were grown at $30^{\circ} \mathrm{C}$ in 2-liter Erlenmeyer flasks containing 1 liter of $2 \times \mathrm{YT}$ culture medium (Sambrook et al. 1989) supplemented with $\mathrm{Km}$ at $25 \mu \mathrm{g} / \mathrm{ml}$. For PmeR production, protein expression was induced at an $\mathrm{OD}_{660}$ of 0.5 to 0.6 by adding $1 \mathrm{mM}$ isopropyl $\beta$ D-1-thiogalactopyranoside. Cells were grown for another $3 \mathrm{~h}$ at $18^{\circ} \mathrm{C}$ and subsequently harvested by centrifugation. The pellet resulting from a 1-liter culture was resuspended in $30 \mathrm{ml}$ of buffer A (20 mM Tris- $\mathrm{HCl}$ [pH 6.4], $20 \mathrm{mM} \mathrm{NaCl}, 5 \%$ [vol/vol] glycerol, $0.1 \mathrm{mM}$ EDTA, and protease inhibitor mixture) (Complete; Diagnostic GmbH, Mannheim, Germany) and broken by treatment with lysozyme and French press at 20 $\mu \mathrm{g} / \mathrm{ml}$. Following centrifugation at $13,000 \times g$ for $60 \mathrm{~min}$, the PmeR protein was predominantly present (more than $80 \%$ ) in 
the soluble fraction. The supernatant was loaded onto a Hitrap Heparin HP column ( $5 \mathrm{ml}$ ) (GE Healthcare, Bio-Sciences AB, Uppsala, Sweden) equilibrated with buffer A and eluted with a gradient of 0.02 to $0.5 \mathrm{M} \mathrm{NaCl}$. Fractions containing PmeR were pooled, concentrated to $4 \mathrm{ml}$ by ultrafiltration using an Amicon 8050 apparatus (Millipore, Billerica, MA, U.S.A., and dialyzed against buffer $\mathrm{B}(20 \mathrm{mM}$ Tris- $\mathrm{HCl}$ [pH 7.5], $250 \mathrm{mM}$ $\mathrm{NaCl}, 10 \%$ [vol/vol] glycerol, $0.1 \mathrm{mM}$ EDTA, and $1 \mathrm{mM}$ dithiothreitol [DTT]). The sample was then submitted to sizeexclusion chromatography using a Sephacryl HR-200 column (GE Healthcare). Eluted fractions of PmeR were pooled, concentrated using the above equipment, and dialyzed against buffer $\mathrm{C}(10 \mathrm{mM}$ Tris-HCl $[\mathrm{pH}$ 7.5], $250 \mathrm{mM} \mathrm{NaCl}, 10 \%$ [vol/vol] glycerol, $0.1 \mathrm{mM}$ EDTA, and $5 \mathrm{mM} \mathrm{DTT}$ ) for protein storage at $-70^{\circ} \mathrm{C}$. Protein concentrations were determined using the Bio-Rad Protein Assay kit.

\section{EMSA.}

The DNA probe was a 263-bp fragment containing the pmeR-mexA intergenic region obtained from DC3000 chromosomal DNA by PCR with the PstI-PpmeR1 (5'-AAAAAACT GCAGAAGACCTCAAAAGATTC-3') and PpmeR-EcoRI.2 (5'-AAAAGAATTCCTCGGGGCAGG-3' pair of primers. The PCR product was isolated from an agarose gel by using the QIAquick Gel Extraction kit (Qiagen) and was radiolabeled at its $5^{\prime}$ ends with $\left[\gamma^{32} \mathrm{P}\right] \mathrm{ATP}$ and T4 polynucleotide kinase. The labeled probe ( $1 \mathrm{nM}$; approximately $10,000 \mathrm{cpm}$ ) was then incubated with the indicated concentrations of purified PmeR in $10 \mu \mathrm{l}$ of STAD (25 mM Tris-acetate [pH 8.0], $8 \mathrm{mM} \mathrm{Mg-}$ acetate, $10 \mathrm{mM} \mathrm{KCl}, 3.5 \%$ [wt/vol] polyethylene glycol- 8000 , and $1 \mathrm{mM}$ DTT) supplemented with poly(dI-dC) at $15 \mu \mathrm{g} / \mathrm{ml}$ and bovine serum albumin at $200 \mu \mathrm{g} / \mathrm{ml}$. When present, effectors were added to the binding reaction mixture at $1 \mathrm{mM}$. The reaction mixtures were incubated for $10 \mathrm{~min}$ at $30^{\circ} \mathrm{C}$, and samples were run on $4.5 \%$ (wt/vol) native polyacrylamide gels (Bio-Rad Mini-Protean II) for $2.5 \mathrm{~h}$ at $60 \mathrm{~V}$ on ice in Tris-borate EDTA. Results were analyzed with Personal FX equipment and Quantity One software (Bio-Rad).

\section{Footprinting assays.}

The DNA probe was the same 263-bp PCR fragment containing the pmeR-mexA intergenic region used in the gel mobility shift assays. For the footprint on the top strand, the PCR was carried out with primers PstI-PpmeR1 (end labeled with $\left[\gamma-{ }^{32} \mathrm{P}\right]$ ATP as described above) and PpmeR-EcoRI.2. For the footprint on the bottom strand, the same primers were used but, in this case, PpmeR-EcoRI.2 was end labeled. Purified labeled probe $(20 \mathrm{nM})$ was incubated without or with PmeR (500 $\mathrm{nM}$ dimer) in a $20-\mu \mathrm{l}$ reaction volume of STAD $(25 \mathrm{mM}$ Tris-acetate [pH 8.0], $8 \mathrm{mM} \mathrm{Mg}$-acetate, $10 \mathrm{mM} \mathrm{KCl}, 3.5 \%$ [wt/vol] polyethylene glycol-8000, and $1 \mathrm{mM}$ DTT) supplemented with poly(dI-dC) at $15 \mu \mathrm{g} / \mathrm{ml}$ and bovine serum albu$\mathrm{min}$ at $200 \mu \mathrm{g} / \mathrm{ml}$. The mixtures were incubated for $10 \mathrm{~min}$ at $30^{\circ} \mathrm{C}$ before being treated with DNase I or DMS, as described previously (Guazzaroni et al. 2004; Rojas et al. 2003).

\section{Infection assays.}

Seed of Solanum lycopersicum 'Moneymaker' (a P. syringae pv. tomato $\mathrm{S}$ line) were germinated and grown with cycles of $16 \mathrm{~h}$ of light, $8 \mathrm{~h}$ of darkness, and $70 \%$ relative humidity. $P$. syringae strains, grown on $\mathrm{LB}$ for $48 \mathrm{~h}$ at $28^{\circ} \mathrm{C}$, were suspended in $10 \mathrm{mM} \mathrm{MgCl} 2$ and the $\mathrm{OD}_{660}$ was adjusted to $0.5\left(10^{8}\right.$ $\mathrm{CFU} / \mathrm{ml}$ ). Further serial dilutions were carried out to obtain a suspension of the desired title for different dose inoculations. Four- to five-week-old plants were inoculated with the bacterial suspension using an airbrush. The control plants were inoculated with a solution of $10 \mathrm{mM} \mathrm{MgCl}_{2}$. For infections, individual inocula $\left(10^{6} \mathrm{CFU} / \mathrm{ml}\right)$ of the strains were sprayed into different plants and the analysis of the evolution of symptoms and sampling were performed $3 \mathrm{~h}$ after inoculation (time 0 , input) and several days after inoculation to determine output CFU. Bacteria were recovered from the infected leaves using a 10 -mm-diameter cork borer. Five disks $\left(3.9 \mathrm{~cm}^{2}\right)$ per plant were homogenized by mechanical disruption into $1 \mathrm{ml}$ of 10 $\mathrm{mM} \mathrm{MgCl}_{2}$ and counted by plating serial dilutions onto LB plates with the corresponding antibiotics.

\section{ACKNOWLEDGMENTS}

This work was supported by grants BFU2007-60272 and BFU200800086 from the Spanish Ministerio de Ciencia e Innovación and P08-CVI3475 from the Junta de Andalucía to M.-T. Gallegos, all of them cofinanced by European Regional Development Fund. P. Vargas was supported by a JAE-Pre fellowship from the CSIC, also cofinanced by European Regional Development Fund. We thank I. Forte for technical assistance.

\section{LITERATURE CITED}

Alguel, Y., Meng, C., Teran, W., Krell, T., Ramos, J. L., Gallegos, M. T., and Zhang, X. 2007. Crystal structures of multidrug binding protein TtgR in complex with antibiotics and plant antimicrobials. J. Mol. Biol. 369:829-840.

Amsterdam, D. 1991. Susceptibility testing of antimicrobials in liquid media. Pages 53-105 in: Antibiotics in Laboratory Medicine, 3rd ed. V. Lorian, ed. Williams and Wilkins, Baltimore.

Aramaki, H., Sagara, Y., Kabata, H., Shimamoto, N., and Horiuchi, T. 1995. Purification and characterization of a cam repressor (CamR) for the cytochrome P-450cam hydroxylase operon on the Pseudomonas putida CAM plasmid. J. Bacteriol. 177:3120-3127.

Barabote, R. D., Johnson, O. L., Zetina, E., san Francisco, S. K., Fralick, J. A., and san Francisco, M. J. D. 2003. Erwinia chrysanthemi tolC is involved in resistance to antimicrobial plant chemicals and is essential for phytopathogenesis. J. Bacteriol. 185:5772-5778.

Blatny, J. M., Brautaset, T., Winther-Larsen, H. C., Haugan, K., and Valla, S. 1997. Construction and use of a versatile set of broad-host-range cloning and expression vectors based on the RK2 replicon. Appl. Environ. Microbiol. 63:370-379.

Brooks, B. E., Piro, K. M., and Brennan, R. G. 2007. Multidrug binding transcription factor QacR binds the bivalent aromatic diamidines DB75 and DB359 in multiple positions. J. Am. Chem. Soc. 129:8389-8395.

Burse, A., Weingart, H., and Ullrich, M. 2004. The phytoalexin-inducible multidrug efflux pump AcrAB contributes to virulence in the fire blight pathogen, Erwinia amylovora. Mol. Plant-Microbe Interact. 17:43-54.

Chuanchuen, R., Narasaki, C. T., and Schweizer, H. P. 2002. The MexJK efflux pump of Pseudomonas aeruginosa requires OprM for antibiotic efflux but not for efflux of triclosan. J. Bacteriol. 184:5036-5044

Cornelis, G. R., and van Gijsegem, F. 2000. Assembly and function of type III secretory systems. Annu. Rev. Microbiol. 54:735-774.

Cuppels, D. A. 1986. Generation and characterization of Tn5 insertion mutations in Pseudomonas syringae pv. tomato. Appl. Environ. Microbiol. 51:323-327.

Cushnie, T. P., and Lamb, A. J. 2005. Antimicrobial activity of flavonoids. Int. J. Antimicrob. Agents 26:343-356. Erratum in: Int. J. Antimicrob. Agents 27:181.

Dixon, R. A. 2001. Natural products and plant disease resistance. Nature 411:843-847.

Enderle, P. J., and Farwell, M. A. 1998. Electroporation of freshly plated Escherichia coli and Pseudomonas aeruginosa cells. Biotechniques 25:954-956, 958.

Eswaran, J., Koronakis, E., Higgins, M. K., Hughes, C., and Koronakis, V. 2004. Three's company: component structures bring a closer view of tripartite drug efflux pumps. Curr. Opin. Struct. Biol. 14:741-747.

Fellay, R., Frey, J., and Krisch, H. 1987. Interposon mutagenesis of soil and water bacteria: a family of DNA fragments designed for in vitro insertional mutagenesis of gram-negative bacteria. Gene 52:147-154.

Fukumori, F., Hirayama, H., Takami, H., Inoue, A., and Horikoshi, K. 1998. Isolation and transposon mutagenesis of a Pseudomonas putida KT2442 toluene-resistant variant: involvement of an efflux system in solvent resistance. Extremophiles 2:395-400.

Grkovic, S., Brown, M. H., Roberts, N. J., Paulsen, I. T., and Skurray, R. A. 1998. QacR is a repressor protein that regulates expression of the Staphylococcus aureus multidrug efflux pump QacA. J. Biol. Chem. 273:18665-18673.

Guazzaroni, M. E., Terán, W., Zhang, X., Gallegos, M. T., and Ramos, J. 
L. 2004. TtgV bound to a complex operator site represses transcription of the promoter for the multidrug and solvent extrusion TtgGHI pump. J. Bacteriol. 186:2921-2927.

Guilfoile, P. G., and Hutchinson, C. R. 1992. The Streptomyces glaucescens $\mathrm{TcmR}$ protein represses transcription of the divergently oriented tcmR and tcmA genes by binding to an intergenic operator region. J. Bacteriol. 174:3659-3666.

Hearn, E. M., Dennis, J. J., Gray, M. R., and Foght, J. M. 2003. Identification and characterization of the emhABC efflux system for polycyclic aromatic hydrocarbons in Pseudomonas fluorescens cLP6a. J. Bacteriol. 185:6233-6240.

Hernández, A., Maté, M. J., Sánchez-Díaz, P. C., Romero, A., Rojo, F., and Martínez, J. L. 2009. Structural and functional analysis of SmeT, the repressor of the Stenotrophomonas maltophilia multidrug efflux pump SmeDEF. J. Biol. Chem. 284:14428-11438.

Hillen, W., and Berens, C. 1994. Mechanisms underlying expression of Tn10 encoded tetracycline resistance. Annu. Rev. Microbiol. 48:345-369.

Hirooka, K., Kunikane, S., Matsuoka, H., Yoshida, K., Kumamoto, K., Tojo, S., and Fujita, Y. 2007. Dual regulation of the Bacillus subtilis regulon comprising the $\operatorname{lm} r A B$ and $y x a G H$ operons and $y x a F$ gene by two transcriptional repressors, LmrA and $\mathrm{YxaF}$, in response to flavonoids. J. Bacteriol. 189:5170-5182.

Johanesen, P. A., Lyras, D., Bannam, T. L., and Rood, J. I. 2001. Transcriptional analysis of the tet $(P)$ operon from Clostridium perfringens. J. Bacteriol. 183:7110-7119.

Kang, H., and Gross, D.C. 2005. Characterization of a resistance-nodulation-cell division transporter system associated with the syr-syp genomic island of Pseudomonas syringae pv. syringae. Appl. Environ. Microbiol. 71:5056-5065

Kim, J., Kim, J. G., Kang, Y., Jang, J. Y., Jog, G. J., Lim, J. Y., Kim, S., Suga, H., Nagamatsu, T., and Hwang, I. 2004. Quorum sensing and the LysR-type transcriptional activator ToxR regulate toxoflavin biosynthesis and transport in Burkholderia glumae. Mol. Microbiol. 54:921-934.

Li, X. Z., and Nikaido, H. 2009. Efflux-mediated drug resistance in bacteria: an update. Drugs 69:1555-1623.

Lisser, S., and Margalit, H. 1993. Compilation of E. coli mRNA promoter sequences. Nucleic Acids Res. 21:1507-1516.

Livak, K. J., and Schmittgen, T. D. 2001. Analysis of relative gene expression data using real-time quantitative PCR and the $2^{-\Delta \Lambda \mathrm{CT}}$ method. Methods 25:402-408.

Lomovskaya, O., Lewis, K., and Matin, A. 1995. EmrR is a negative regulator of the Escherichia coli multidrug resistance pump EmrAB. J. Bacteriol. 177:2328-34.

Ma, D., Alberti, M., Lynch, C., Nikaido, H., and Hearst, J. E. 1996. The local repressor AcrR plays a modulating role in the regulation of acrAB genes of Escherichia coli by global stress signals. Mol. Microbiol. 19:101-112.

Madoori, P. K., Agustiandari, H., Driessen, A. J., and Thunnissen, A. M. 2009. Structure of the transcriptional regulator LmrR and its mechanism of multidrug recognition. EMBO (Eur. Mol. Biol. Organ.) J. 28:156-166.

Maggiorani-Vallecillos, A., Rodríguez-Palenzuela, P., and López-Solanilla, E. 2006. The role of several multidrug resistance systems in Erwinia chrysanthemi pathogenesis. Mol. Plant-Microbe Interact. 19:607-613.

Michán, C., and Pueyo, C. 2009. Growth phase-dependent variations in transcript profiles for thioredoxin- and glutathione-dependent redox systems followed by budding and hyphal Candida albicans cultures. Yeast Res. 9:1078-1090.

Miller, J. H. 1972. Experiments in Molecular Genetics. Cold Spring Harbor Laboratory Press, Cold Spring Harbor, NY, U.S.A.

Murakami, S., Nakashima, R., Yamashita, E., Matsumoto, T., and Yamaguchi, A. 2006. Crystal structures of a multidrug transporter reveal a functionally rotating mechanism. Nature 443:173-179.

Murray, D. S., Schumacher, M. A., and Brennan, R. G. 2004. Crystal structures of QacR-diamidine complexes reveal additional multidrugbinding modes and a novel mechanism of drug charge neutralization. J. Biol. Chem. 279:14365-14371.

Ohemeng, K. A., Schwender, C. F., Fu, K. P., Barrett, J. F. 1993. DNA gyrase inhibitory and antibacterial activity of some flavones. Bioorg.
Med. Chem. Lett. 3:225-230.

Orth, P., Schnappinger, D., Hillen, W., Saenger, W., and Hinrichs, W. 2000. Structural basis of gene regulation by the tetracycline inducible Tet repressor-operator system. Nat. Struct. Biol. 7:215-219.

Osbourn, A. E. 1996. Preformed antimicrobial compounds and plant defense against fungal attack. Plant Cell 8:1821-1831.

Palumbo, J. D., Kado, C. I., and Phillips, D. A. 1998. An isoflavonoidinducible efflux pump in Agrobacterium tumefaciens is involved in competitive colonization of roots. J. Bacteriol. 180:3107-3113.

Papler, A., Golob, M., Hafner, I., Oblak, M., Solmajer, T., and Jerala, R. 2003. Characterization of quercetin binding site on DNA gyrase. Biochem. Biophys. Res. Commun. 306:530-536.

Poole, K. 2003. Overcoming multidrug resistance in gram-negative bacteria. Curr. Opin. Invest. Drugs 4:128-139

Poole, K., Tetro, K., Zhao, Q., Neshat, S., Heinrichs, D. E., and Bianco, N. 1996. Expression of the multidrug resistance operon mexA-mexB-oprM in Pseudomonas aeruginosa: mexR encodes a regulator of operon expression. Antimicrob. Agents Chemother. 40:2021-2028.

Ramos, J. L., Duque, E., Godoy, P., and Segura, A. 1998. Efflux pumps involved in toluene tolerance in Pseudomonas putida DOT-T1E. J. Bacteriol. 180:3323-3329.

Ramos, J. L., Martínez-Bueno, M., Molina-Henares, A. J., Terán, W., Watanabe, K., Zhang, X., Gallegos, M. T., Brennan, R., and Tobes, R. 2005. The TetR family of transcriptional repressors. Microbiol. Mol. Biol. Rev. 69:326-356.

Rojas, A., Segura, A., Guazzaroni, M. E., Terán, W., Hurtado, A., Gallegos, M. T., and Ramos, J. L. 2003. In vivo and in vitro evidence that $\mathrm{TtgV}$ is the specific regulator of the TtgGHI multidrug and solvent efflux pump of Pseudomonas putida. J. Bacteriol. 185:4755-4763.

Saier, M. H., Jr., and Paulsen, I. T. 2001. Phylogeny of multidrug transporters. Semin. Cell Dev. Biol. 12:205-213.

Sambrook, J., Fritsch, E. F., and Maniatis, T. 1989. Molecular Cloning: A Laboratory Manual. Cold Spring Harbor Laboratory Press, Cold Spring Harbor, NY, U.S.A

Schumacher, M. A., Miller, M. C., Grkovic, S., Brown, M. H., Skurray, R. A., and Brennan, R. G. 2001. Structural mechanisms of QacR induction and multidrug recognition. Science 294:2158-2163.

Schumacher, M. A., Miller, M. C., Grkovic, S., Brown, M. H., Skurray, R. A., and Brennan, R. G. 2002. Structural basis for cooperative DNA binding by two dimers of the multidrug-binding protein QacR. EMBO (Eur. Mol. Biol. Organ.) J. 21:1210-1218. Erratum in: EMBO J. 21:2301.

Schumacher, M. A., Miller, M. C., and Brennan, R. G. 2004. Structural mechanism of the simultaneous binding of two drugs to a multidrugbinding protein. EMBO (Eur. Mol. Biol. Organ.) J. 23:2923-2930.

Spaink, H. P., Okker, R. J. H., Wijffelman, C. A., Pees, E., and Lugtenberg, B. J. J. 1987. Promoters in the nodulation region of the Rhizobium leguminosarum Sym plasmid pRL1JI. Plant Mol. Biol. 9:27-39.

Stoitsova, S. O., Braun, Y., Ullrich, M. S., and Weingart, H. 2008. Characterization of the RND-type multidrug efflux pump MexAB-OprM of the plant pathogen Pseudomonas syringae. Appl. Environ. Microbiol. 74:3387-3393.

Terán, W., Felipe, A., Segura, A., Rojas, A., Ramos, J. L., and Gallegos, M. T. 2003. The antimicrobial agent efflux pump TtgABC of the solvent-tolerant Pseudomonas putida DOT-T1E is induced by the presence of structurally different antibiotics. Antimicrob. Agents Chemother. 47:3067-3072.

Terán, W., Krell, T., Ramos, J. L., Gallegos, M. T. 2006. Effector-repressor interactions, binding of a single effector molecule to the operator-bound TtgR homodimer mediates derepression. J. Biol. Chem. 281:71027109 .

Van Etten, H., Temporini, E., and Wasmann, C. 2001. Phytoalexin (and phytoanticipin) tolerance as a virulence trait: why is it not required by all pathogens? Physiol. Mol. Plant Pathol. 59:83-93.

Yu, Z., Reichheld, S. E., Savchenko, A., Parkinson, J., and Davidson, A. R. 2010. A comprehensive analysis of structural and sequence conservation in the TetR family transcriptional regulators. J. Mol. Biol. 400:847864. 